\title{
DOCK6 Mutations are Responsible for a Distinct Autosomal Recessive Variant of Adams-Oliver Syndrome Associated with Brain and Eye Anomalies
}

\begin{tabular}{|c|c|}
\hline Journal: & Human Mutation \\
\hline Manuscript ID: & humu-2014-0525.R1 \\
\hline Wiley - Manuscript type: & Brief Report \\
\hline Date Submitted by the Author: & $n / a$ \\
\hline Complete List of Authors: & $\begin{array}{l}\text { Sukalo, Maja; University Hospital Magdeburg, Institute of Human Genetics } \\
\text { Tilsen, Felix; University Hospital Magdeburg, Institute of Human Genetics } \\
\text { Kayserili, Hulya; Istanbul Medical Faculty, Medical Genetics Department } \\
\text { Müller, Dietmar; Klinikum Chemnitz, Institut für Medizinische Genetik } \\
\text { Tuysuz, Beyhan; Istanbul University, Department of Pediatric Genetics } \\
\text { Ruddy, Deborah; Guy's Hospital, Department of Clinical Genetics } \\
\text { Wakeling, Emma; North West London Hospitals NHS Trust, North West } \\
\text { Thames Regional Genetics Service } \\
\text { Ørstavik, Karen; Oslo University Hospital, Department of Medical Genetics } \\
\text { Snape, Katie; St George's Healthcare NHS Trust, Department of Clinical } \\
\text { Genetics } \\
\text { Trembath, Richard; Queen Mary University of London, Barts and The } \\
\text { London School of Medicine and Dentistry } \\
\text { De Smedt, Maryse; Leuven University Hospital, Deptartment of Medical } \\
\text { Genetics } \\
\text { van der Aa, Nathalie; Antwerp University Hospital, Department of Medical } \\
\text { Genetics } \\
\text { Skalej, Martin; University Hospital Magdeburg, Institute of Neuroradiology } \\
\text { Mundlos, Stefan; Universitätsmedizin Berlin and Max Planck Institute for } \\
\text { Molecular Genetics Berlin, Institute for Medical and Human Genetics } \\
\text { Charité } \\
\text { Wuyts, Wim; Antwerp University Hospital, Department of Medical Genetics; } \\
\text { University of Antwerp, Department of Medical Genetics } \\
\text { Southgate, Laura; Queen Mary University of London, Barts and The London } \\
\text { School of Medicine and Dentistry; King's College London, Division of } \\
\text { Genetics and Molecular Medicine } \\
\text { Zenker, Martin; University Hospital Magdeburg, Institute of Human } \\
\text { Genetics }\end{array}$ \\
\hline Key Words: & $\begin{array}{l}\text { Adams-Oliver syndrome, DOCK6, autosomal recessive, brain anomalies, } \\
\text { eye anomalies }\end{array}$ \\
\hline
\end{tabular}




1
2
3
4
5
6
7
8
9
10
11
12
13
14
15
16
17
18
19
20
21
22
23
24
25
26
27
28
29
30
31
32
33
34
35
36
37
38
39
40
41
42
43
44
59
45
46
47
48
49
50
51
52
54
56

SCHOLARONE ${ }^{m}$

Manuscripts

7

8

10

11

13

14

15

16

18

19

20

22

24

26

27

29

32

33

34

35

36

39

40

41

42

44

45

46

47

48

49

51

52

53

54

56

57

58

60

John Wiley \& Sons, Inc. 


\section{BRIEF REPORT}

\section{DOCK6 Mutations are Responsible for a Distinct Autosomal Recessive Variant of Adams-Oliver Syndrome Associated with Brain and Eye} Anomalies

Maja Sukalo $^{1 \dagger^{*}}$, Felix Tilsen ${ }^{1 \dagger}$, Hülya Kayserili ${ }^{2}$, Dietmar Müller ${ }^{3}$, Beyhan Tüysüz ${ }^{4}$, Deborah M. Ruddy ${ }^{5}$, Emma Wakeling 6 , Karen Helene Ørstavik ${ }^{7}$, Katie M. Snape ${ }^{8}$, Richard Trembath $^{5,9}$, Maryse De Smedt ${ }^{10}$, Nathalie van der $\mathrm{Aa}^{11}$, Martin Skalej ${ }^{12}$, Stefan Mundlos ${ }^{13}$, Wim Wuyts ${ }^{11,14 \#}$, Laura Southgate ${ }^{9,15 \#}$, Martin Zenker ${ }^{1 \#}$

${ }^{\dagger}$ These authors contributed equally as first authors

\# These authors contributed equally as senior authors

${ }^{1}$ Institute of Human Genetics, University Hospital Magdeburg, Magdeburg, Germany

${ }^{2}$ Medical Genetics Department, Istanbul Medical Faculty, Istanbul, Turkey

${ }^{3}$ Institut für Medizinische Genetik, Klinikum Chemnitz, Chemnitz, Germany

${ }^{4}$ Department of Pediatric Genetics, Istanbul University, Istanbul, Turkey

${ }^{5}$ Department of Clinical Genetics, Guy's Hospital, London, UK

${ }^{6}$ North West Thames Regional Genetics Service, North West London Hospitals NHS Trust, Harrow, UK

${ }^{7}$ Department of Medical Genetics, Oslo University Hospital, Oslo, Norway

${ }^{8}$ Department of Clinical Genetics, St George's Healthcare NHS Trust, London, UK

${ }^{9}$ Barts and The London School of Medicine and Dentistry, Queen Mary University of London, London, UK

${ }^{10}$ Department of Medical Genetics, Leuven University Hospital, Leuven, Belgium

${ }^{11}$ Department of Medical Genetics, Antwerp University Hospital, Antwerp, Belgium

${ }^{12}$ Institute of Neuroradiology, University Hospital Magdeburg, Magdeburg, Germany 
${ }^{13}$ Institute for Medical and Human Genetics Charité, Universitätsmedizin Berlin and Max

Planck Institute for Molecular Genetics Berlin, Berlin, Germany

${ }^{14}$ Department of Medical Genetics, University of Antwerp, Antwerp, Belgium

${ }^{15}$ Division of Genetics and Molecular Medicine, King's College London, London, UK

Contract grant sponsor: German Research Foundation, DFG ZE 524/2-3

*Corresponding Author:

Maja Sukalo

Institute of Human Genetics

University Hospital Magdeburg

Leipziger Straße 44

39120 Magdeburg

Germany

E-mail: Maja.Sukalo@med.ovgu.de 


\section{Abstract}

Adams-Oliver syndrome (AOS) is characterized by the association of aplasia cutis congenita with terminal transverse limb defects, often accompanied by additional cardiovascular or neurological features. Both autosomal dominant and recessive disease transmission have been observed, with recent gene discoveries indicating extensive genetic heterogeneity. Mutations of the DOCK6 gene were first described in autosomal recessive cases of AOS and only five DOCK6-related families have been reported to date. Recently, a second type of autosomal recessive AOS has been attributed to EOGT mutations in three consanguineous families. Here, we describe the identification of 13 DOCK6 mutations, the majority of which are novel, across 10 unrelated individuals from a large cohort comprising 47 sporadic cases and 31 AOS pedigrees suggestive of autosomal recessive inheritance. DOCK6 mutations were strongly associated with structural brain abnormalities, ocular anomalies, and intellectual disability, thus suggesting that DOCK6-linked disease represents a variant of AOS with a particularly poor prognosis.

Keywords: Adams-Oliver syndrome, DOCK6, autosomal recessive, brain anomalies, eye anomalies. 
First described in 1945, Adams-Oliver syndrome (AOS) is characterized by the combination of terminal transverse limb defects (TTLD) and aplasia cutis congenita (ACC) typically located in the midline parietal and/or occipital region of the scalp [Adams and Oliver, 1945]. Structures underlying these defects (skull bones, meninges, sinus) may also be involved. AOS is often associated with additional congenital vascular anomalies such as cutis marmorata telangiectatica congenita (CMTC), reported in around $20 \%$ of patients, pulmonary hypertension, and lesions of presumed vascular etiology in other organs. Moreover, around $20 \%$ of patients with AOS have congenital cardiac defects including - amongst others - aortic valve anomalies, septal defects and tetralogy of Fallot [Snape et al., 2009]. The spectrum of congenital anomalies observed in AOS has led to the hypothesis that disturbed vasculogenesis may underlie this disorder [Swartz et al., 1999]. AOS is emerging as a very heterogeneous disorder, both clinically and genetically. To date, three genes have already been identified as causative for the autosomal dominant form, namely ARHGAP31 (MIM *610911; AOS1; \#100300) [Southgate et al., 2011], RBPJ (MIM *147183; AOS3; \#614814) [Hassed et al., 2012], and NOTCH1 (MIM *190198; AOS5; \#616028) [Stittrich et al., 2014]. Two genes, DOCK6 (MIM *614194; AOS2; \#614219) [Shaheen et al., 2011] and EOGT (MIM *614789; AOS4; \#615297) [Shaheen et al., 2013], have been reported in pedigrees with autosomal recessive transmission of AOS. Each of these genes apparently accounts for only a minor proportion of patients. It is therefore likely that further AOS genes will be identified in the future.

Homozygous or compound heterozygous DOCK6 mutations have so far been reported in only four inbred Arab families [Shaheen et al., 2011, 2013] and in a single sporadic patient [Lehman et al., 2014], respectively. The DOCK6 protein belongs to the conserved dedicator of cytokinesis family and has a role in remodeling the actin cytoskeleton by acting as a guanine nucleotide exchange factor (GEF) for two members of the Rho GTPase family, Cdc42 and Rac1 [Miyamoto et al., 2007]. This regulation of Cdc42 and Rac1 complements 
the GTPase-activating protein (GAP) activity of the gene product of ARHGAP31 [Tcherkezian et al., 2006], mutations of which underlie some autosomal dominant cases of AOS [Southgate et al., 2011; Isrie et al., 2014], thus pointing at abnormal cytoskeleton remodeling as one of the basic pathogenic mechanisms leading to AOS.

To further understand the role of DOCK6 in the etiology of this disorder and to establish possible phenotype correlations, we performed a comprehensive mutation screen of this gene in a large and heterogeneous patient cohort. The study cohort consisted of 88 patients from 78 unrelated families recruited by the partners of the AOS Collaborative Group. The presence of both ACC and TTLD in at least one affected family member served as minimal clinical inclusion criteria for this study, with the exception of one case that has been previously published as a variant of AOS with cognitive impairment, but without scalp defect [Brancati et al., 2008]. Additional physical abnormalities were reported in a considerable proportion of patients and included cerebral $(n=19)$, ocular $(n=13)$, neurodevelopmental $(n=25)$, and cardiac anomalies $(n=14)$. Either sporadic cases of AOS $(n=47)$ or those with a pedigree constellation suggestive of autosomal recessive disease transmission $(n=31)$ were included. Parental consanguinity and/or the presence of multiple affected children of clinically unaffected parents were regarded as possible indicators of autosomal recessive inheritance. Families with parent-child transmission of the phenotype suggesting autosomal dominant inheritance were excluded. DOCK6 mutation screening was performed by PCR and conventional sequencing of all 48 coding exons and flanking intronic regions (Supp. Materials and Methods). The study was approved by the institutional review boards of the participating centers, University of Magdeburg/Erlangen, Guy’s and St Thomas' Hospitals London, and University of Antwerp. Written informed consent was obtained from the patients and/or the parents. Mutations, unclassified variants and phenotype data were submitted to the Leiden Open Variation Database (http://databases.lovd.nl/). 
In this cohort we detected 10 unrelated individuals with biallelic sequence changes in DOCK6 that were classified as probable pathogenic mutations. Seven of those patients were offspring of consanguineous parents, two originated from non-consanguineous families with multiple affected children, and one was a sporadic case with no known parental consanguinity (Supp. Figure S1). The overall proportion of DOCK6-related AOS across our complete cohort was $13 \%$, with a frequency of $29 \%(9 / 31)$ among the families suggestive of autosomal recessive inheritance and $2 \%(1 / 47)$ in sporadic cases with no parental consanguinity. Our findings thus underscore the importance of DOCK6 as a gene for autosomal recessive AOS. They also suggest that a small proportion of apparently sporadic cases are in fact recessive with DOCK6 as the underlying etiology.

The mutations observed in these 10 families included nonsense $(n=1)$, missense $(n=4)$, frameshift $(n=4)$, and splice site mutations $(n=3)$, as well as one larger intragenic deletioninsertion resulting in deletion of exons 42 to 47 . The latter was identified through the failure to amplify the terminal exons by PCR and confirmed by focused MLPA and breakpoint sequencing (Supp. Figure S1, family 9). Eleven of these 13 mutations were novel and two have been previously described as causative of AOS [Shaheen et al., 2011, 2013] (Figure 1A and Supp. Table S1). Seven index patients had homozygous mutations consistent with selfstated parental consanguinity, while the remaining three had compound heterozygous changes. Of the four missense mutations observed in this cohort, three were homozygous in affected children from consanguineous families (c.3047T $>$ C, p.Leu1016Pro; c.3154G $>$ A, p.Glu1052Lys; c.4786C >T, p.Arg1596Trp) and one (c.788T $>$ A, p.Val263Asp) occurred in compound heterozygosity with a splice site mutation on the second allele. All four missense variations were classified as likely causative mutations on the basis of conservation of the affected residue, as assessed by various online prediction tools (Supp. Table S2). Moreover, in the consanguineous family harboring the missense mutation p.Leu1016Pro (c.3047T $>$ C, family 1), previous homozygosity mapping using a SNP array had been consistent with 
linkage to the DOCK6 locus in the index patient, demonstrating a $22 \mathrm{Mb}$ stretch of autozygosity on chromosome 19 (data not shown). In one pedigree (family 6), segregation of compound heterozygosity for the missense mutation p.Val263Asp and a splice site mutation on the second allele (c.5939+2T $>$ C) was confirmed in the two affected siblings (Table 1, Supp. Figure S1). Of the three splice site mutations observed in this study, one $(\mathrm{c} .4106+5 \mathrm{G}>\mathrm{T})$ is outside of the canonical splice site dinucleotide. Unfortunately, no appropriate material could be obtained to prove the splicing effect on the mRNA level. However, compound heterozygosity for this change and a frameshift mutation on the other allele was found to segregate with the phenotype in family 7 (Table 1, Supp. Figure S1). Furthermore, splice prediction tools consistently calculated that this change likely abrogated splice donor function at this site (Supp. Table S3), thus supporting the likely pathogenic role of this variation. To date, six distinct DOCK6 mutations have been reported to underlie the AOS type 2 (Figure 1A, Supp. Table S1), with loss of function or expression of the DOCK6 protein suggested as the basic pathogenic mechanism [Shaheen et al., 2011, 2013; Lehman et al., 2014]. Taken together with previous reports, this study demonstrates that DOCK6 mutations are distributed over the entire gene with no obvious clustering to certain domains of the encoded protein (Figure 1A). A deleterious effect on the gene product is plausible for most of these changes, as they are predicted to lead to either a truncated protein or nonsensemediated mRNA decay. However, the precise functional consequences of the novel missense mutations presented here remain to be explored.

In addition to the pathogenic mutations described above, we also identified 16 heterozygous DOCK6 sequence variations in our cohort, which remained as unclassified due to either uncertain clinical significance or annotation in dbSNP (build 139) as rare variants (MAF <0.01) (Supp. Table S4). These variants included predicted amino acid substitutions $(n=8)$, synonymous alterations in the coding sequence $(n=5)$, and intronic substitutions within $20 \mathrm{bp}$ of the splice site $(\mathrm{n}=3)$. None of these variations were unambiguously classified as 
disease-causing by prediction tools. Thirteen unrelated sporadic cases harbored a single heterozygous unclassified DOCK6 variant, while two patients were found to have two or more variants. Of these, one case had inherited both variants $($ c. $885 \mathrm{C}>\mathrm{T}, \mathrm{p} .(=)$ and c.2104G $>$ A, p.Gly702Ser) from the mother on the same allele (data not shown). Another patient was found to harbor three unclassified variants (c.885C $>$ T, p. $(=)$; c.1289G $>A$, p.Arg430His; c.1833-19C >G), the segregation of which could not be studied. Notably, this patient was previously reported in the literature as a variant subtype of AOS associated with cerebral anomalies, seizures and severe MR, but without ACC of the scalp [Brancati et al., 2008]. While most of these variations are more likely to be non-pathogenic (Supp. Table S5), we cannot fully exclude any contribution to the observed phenotype. Our mutation screening strategy did not assess mutations of the promoter and intronic changes. We also did not systematically screen for larger genomic deletions/duplications. Therefore, it remains possible that additional pathogenic variants may have been missed in this cohort and that the given figure of the contribution of DOCK6-related disease is somewhat underestimated. However, for the DOCK6 mutation-negative patients originating from consanguineous families we can state that five had a previous SNP array analysis showing no suggestive stretch of homozygosity at the DOCK6 locus (data not shown). In two out of four further subjects who had no previous homozygosity mapping, DOCK6 sequencing revealed at least one heterozygous SNP, whilst for two cases, sequencing results were uninformative in excluding homozygosity at the DOCK6 gene locus. Thus, at least for our consanguineous families we can conclude that genes other than DOCK6 are very likely involved in the pathogenesis of AOS. Mutations of the EOGT gene may account for part of our DOCK6-negative AOS cases [Shaheen et al., 2013]; however mutation screening of this gene was not within the scope of this study. It also remains to be seen whether further recessive AOS genes will be identified in due course. Moreover, considering the inclusion criteria for this study, it is possible that a proportion of our cohort may in fact represent dominant de novo mutations or, in the case of 
affected siblings with asymptomatic parents, autosomal dominant inheritance with incomplete penetrance.

The main clinical findings of the DOCK6-positive individuals from our cohort are summarized in Table 1. Detailed clinical data could be obtained from 10 patients originating from eight families. The patients' ages ranged between one week and 20 years (median 4.3 years). All except one affected individual from these families had ACC of the scalp and TTLD of variable expression; patient 7.2 presented only with mild hypoplasia of toenails along with a congenital heart defect, impaired vision and mild cognitive impairment, whereas his sister presented with classic AOS features including ACC and TTLD. Across our DOCK6positive cohort, the limb defects ranged from minimal hypoplasia of terminal phalanges to severe transverse reduction defects (Figure 1B). Notably, aside from ACC typically located on the scalp vertex, four patients had additional areas of ACC on the abdomen. Further associated anomalies, primarily related to the nervous system, were present in all individuals carrying homozygous or compound-heterozygous DOCK6 mutations. Specifically, all patients from whom sufficient data could be obtained were reported with developmental delay or mental retardation, ranging from mild to severe (Table 1). A broad range of additional neurological abnormalities were reported in most cases, including cerebral palsy, spasticity, contractures, and epilepsy. Only one patient aged $\geq 4$ years had achieved the ability to walk without support. Behavioral abnormalities including autistic behavior or temper tantrums were reported in two patients. Brain MRI or CT had been performed for seven patients and was abnormal in all cases. The most frequent changes observed on brain imaging included ventriculomegaly, periventricular leukomalacia/calcifications, and hypoplasia/atrophy of the corpus callosum (Table 1). Images from five affected individuals are exemplarily shown in Figure 1C. Patient 4.1 underwent cerebral ultrasonography at 3 months of age which also showed ventriculomegaly. A further patient (6.2) was previously reported with ventricular dilatation, partial agenesis of the corpus callosum, and periventricular leukomalacia on 
autopsy [Orstavik et al., 1995]. Where available, measurements of head circumference were in the microcephalic range for all eight patients. Ocular anomalies including microphthalmia, retinal detachment, and visual impairment were reported in all patients for whom clinical information was obtainable. In contrast, cardiac anomalies were observed in only three cases.

Taken together, the most striking phenotypic attribute of DOCK6-related AOS in the presented cohort is the strong association with important neurodevelopmental and ocular anomalies. The pattern of neurological impairment and most of the reported morphological changes (microcephaly, ventricular dilatation, periventricular calcifications, cortical changes) are suggestive of a disruptive vascular pathogenesis rather than a primary maldevelopment of the brain. Lesions classified as calcifications according to density analysis, may represent primary calcifications but can in fact also have resulted from previous microbleeds. Likewise, the main ocular anomalies observed in our DOCK6-positive patients, namely microphthalmia and retinal detachment, are compatible with a disruptive vasculogenesis. The high prevalence of brain and eye abnormalities as well as the pattern of cerebral and ocular involvement is in line with previous case reports (Table 1). However the data on the previously reported patients do not provide specific detail to definitely state that brain involvement is a constant feature in AOS type 2. While DOCK6 mutations are generally a rare cause of AOS, in our cohort they accounted for $8 / 25(32 \%)$ cases presenting with major neurodevelopmental defects and for 9/19 (47\%) cases with documented brain abnormalities. Taken together, these data suggest that DOCK6 mutations are particularly responsible for a variant of AOS characterized by ACC, TTLD plus cerebral and ocular abnormalities. The existence of such a variant was previously postulated nearly 20 years ago [Orstavik et al., 1995] and our study now confirms that DOCK6 is indeed the gene responsible for the disease in that family (family 6). The strong association of DOCK6 mutations with anomalies of the brain and eye implies that deleterious effects on angiogenesis caused by DOCK6 deficiency also affect development of these particular structures. In their review, Snape et al. concluded that 
abnormal brain and ocular findings are more common in autosomal recessive AOS [Snape et al., 2009]. It is becoming clear that the individuals with DOCK6 mutations account for a substantial part for this observation. By contrast, among five patients with EOGT mutations, only one patient was reported to have brain anomalies and no abnormal ocular findings were reported in any subject [Shaheen et al., 2013]. Nonetheless, across our complete cohort, approximately two-thirds of the AOS patients with major neurodevelopmental disorders and about half of the cases with structural brain anomalies could not be explained by DOCK6 mutations, thus suggesting that the association with a neurological phenotype is not specific to AOS type 2 .

In summary, by presenting 10 novel families with DOCK6 mutations, we substantially expand the clinical and mutational spectrum of AOS type 2. Our findings provide independent corroboration that mutations in DOCK6 are responsible for nearly one third of autosomal recessively inherited AOS and that this genetic entity also accounts for a minority of sporadic cases. AOS type 2 is particularly if not consistently associated with cerebral and ocular anomalies in addition to ACC and TTLD. In patients with such a constellation of symptoms DOCK6 should therefore be the primary candidate gene for molecular investigation.

\section{Acknowledgements}

The authors thank the participating families and the clinicians who recruited patients to the European AOS Consortium (M. Aglam, L. Al-Gazali, D. Amor, S. Beekman, F. Brancati, G. Breisch-Lotz, W. Coerdt, B. De Vries, J. Desir, L. Fayol, L. Graul-Neumann, Z. Gucev, U. Hehr, M. Holder, D. Horn, E. Jacquemin, S. Janssens, A. Kariminejad, E. Kinning, Y. Lacassie, C. Li, V. López González, S. Lynch, L. McGregor, V. Meiner, I. Navarro, S. Mercier, S. Odent, M. Patel, L. Pinson, K. Prescott, W. Reardon, C. Rusu, M. Splitt, C. Tertilt, E. Thompson, J. Tolmie, J. van den Ende, L. van Maldergem, A. Weber, M. 
Whiteford, M. Willems). We also thank Ilka Kramer, Susan Engelberg, and Nicole Epperlein for excellent technical support, and J. Westvik for his kind collaboration.

1

2

3

4

5

6

7

8

9

10

11

12

13

14

15

16

17

18

19

20

21

22

23

24

25

26

27

28

29

30

31

32

33

34

35

36

37

38

39

40

41

42

43

44

45

46

47

48

49

50

51

52

53

54

55

56

57

58

59

60

John Wiley \& Sons, Inc. 


\section{References}

Adams FH, Oliver CP. 1945. Hereditary deformities in man due to arrested development. J Hered 36:3-7.

Brancati F, Garaci FG, Mingarelli R, Dallapiccola B. 2008. Abnormal neuronal migration defect in the severe variant subtype of Adams-Oliver syndrome. Am J Med Genet A 146A:1622-3.

Cote JF, Vuori K. 2002. Identification of an evolutionarily conserved superfamily of DOCK180-related proteins with guanine nucleotide exchange activity. J Cell Sci 115:4901-13.

Hassed SJ, Wiley GB, Wang S, Lee JY, Li S, Xu W, Zhao ZJ, Mulvihill JJ, Robertson J, Warner J, Gaffney PM. 2012. RBPJ mutations identified in two families affected by Adams-Oliver syndrome. Am J Hum Genet 91:391-5.

Isrie M, Wuyts W, Van Esch H, Devriendt K. 2014. Isolated terminal limb reduction defects: extending the clinical spectrum of Adams-Oliver syndrome and ARHGAP31 mutations. Am J Med Genet A 164A:1576-9.

Lehman A, Stittrich AB, Glusman G, Zong Z, Li H, Eydoux P, Senger C, Lyons C, Roach JC, Patel M. 2014. Diffuse angiopathy in Adams-Oliver syndrome associated with truncating DOCK6 mutations. Am J Med Genet A 164A:2656-62.

Miyamoto Y, Yamauchi J, Sanbe A, Tanoue A. 2007. Dock6, a Dock-C subfamily guanine nucleotide exchanger, has the dual specificity for Rac1 and $\mathrm{Cdc} 42$ and regulates neurite outgrowth. Experimental cell research 313:791-804.

Orstavik KH, Stromme P, Spetalen S, Flage T, Westvik J, Vesterhus P, Skjeldal O. 1995. Aplasia cutis congenita associated with limb, eye, and brain anomalies in sibs: a variant of the Adams-Oliver syndrome? Am J Med Genet 59:92-5. 
Prothero J, Nicholl R, Wilson J, Wakeling EL. 2007. Aplasia cutis congenita, terminal limb defects and falciform retinal folds: confirmation of a distinct syndrome of vascular disruption. Clin Dysmorphol 16:39-41.

Shaheen R, Faqeih E, Sunker A, Morsy H, Al-Sheddi T, Shamseldin HE, Adly N, Hashem M, Alkuraya FS. 2011. Recessive mutations in DOCK6, encoding the guanidine nucleotide exchange factor DOCK6, lead to abnormal actin cytoskeleton organization and Adams-Oliver syndrome. Am J Hum Genet 89:328-33.

Shaheen R, Aglan M, Keppler-Noreuil K, Faqeih E, Ansari S, Horton K, Ashour A, Zaki MS, Al-Zahrani F, Cueto-Gonzalez AM, Abdel-Salam G, Temtamy S, et al. 2013. Mutations in EOGT confirm the genetic heterogeneity of autosomal-recessive AdamsOliver syndrome. Am J Hum Genet 92:598-604.

Snape KM, Ruddy D, Zenker M, Wuyts W, Whiteford M, Johnson D, Lam W, Trembath RC. 2009. The spectra of clinical phenotypes in aplasia cutis congenita and terminal transverse limb defects. Am J Med Genet A 149A:1860-81.

Southgate L, Machado RD, Snape KM, Primeau M, Dafou D, Ruddy DM, Branney PA, Fisher M, Lee GJ, Simpson MA, He Y, Bradshaw TY, et al. 2011. Gain-of-function mutations of ARHGAP31, a Cdc42/Rac1 GTPase regulator, cause syndromic cutis aplasia and limb anomalies. Am J Hum Genet 88:574-85.

Stittrich AB, Lehman A, Bodian DL, Ashworth J, Zong Z, Li H, Lam P, Khromykh A, Iyer RK, Vockley JG, Baveja R, Silva ES, et al. 2014. Mutations in NOTCH1 Cause Adams-Oliver Syndrome. Am J Hum Genet 95:275-84.

Swartz EN, Sanatani S, Sandor GG, Schreiber RA. 1999. Vascular abnormalities in AdamsOliver syndrome: cause or effect? Am J Med Genet 82:49-52.

Tcherkezian J, Triki I, Stenne R, Danek EI, Lamarche-Vane N. 2006. The human orthologue of CdGAP is a phosphoprotein and a GTPase-activating protein for Cdc42 and Rac1 but not RhoA. Biol Cell 98:445-56. 


\section{Figure Legend}

Figure 1: (A) DOCK6 protein with known functional domains and distribution of mutations. The protein contains two DOCK homology regions, DHR-1 and DHR-2. DHR-1 spans about 200 amino acids at the N-terminal end of the protein, whereas DHR-2 is located towards the C-terminus and has an approximate length of 500 amino acids [Cote and Vuori, 2002]. All currently known mutations are displayed according to their location in the DOCK6 protein. Red represents nonsense mutations $(n=3)$, black indicates frameshift mutations $(n=5)$, missense mutations are shown in green $(n=4)$, splice site mutations are colored in orange $(n=4)$ and the blue line represents one large deletion insertion at the C-terminal end of the DOCK6 protein spanning exons 42 to 47 . Novel mutations reported in this paper are written in italics. (B) Clinical photographs of three DOCK6-positive individuals with AOS from this cohort showing areas of alopecia on the vertex resulting from aplasia cutis congenita and terminal defects of the digits of varying severity. (C) Brain imaging of AOS patients with DOCK6 mutations. Cranial MRI of patient 2.1 at age 1 year: T2-weighted axial section showing enlarged lateral ventricles and cerebral atrophy particularly affecting the frontal lobe, and contrast enhanced T1-weighted median sagittal section illustrating thin corpus callosum and enlarged basal subarachnoid spaces. CT scan of patient 3.1 at age 6 years: Axial sections showing ventriculomegaly and periventricular calcifications, and orbital section showing right microphthalmia with interocular hyperdensities representing retinal detachment and cystic malformation of the anterior chamber. T1-weighted MRI of patient 5.1 at age 3 years: Axial sections showing irregularly shaped and slightly dilated lateral ventricles. Axial CT scan of patient 6.1 in neonatal period showing ventricular dilatation and multiple periventricular calcifications. Brain imaging of patient 10.1: CT scan at age 2 years showing periventricular calcifications, and T2-weighted MRI axial section age 3 years showing irregularly shaped, slightly enlarged ventricles and mild atrophy of the brain. MRI, magnetic resonance imaging, CT, computed tomography. 


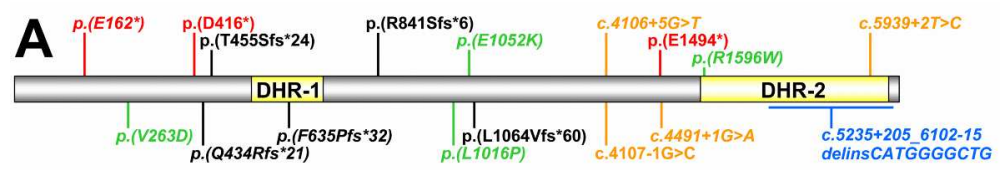

B
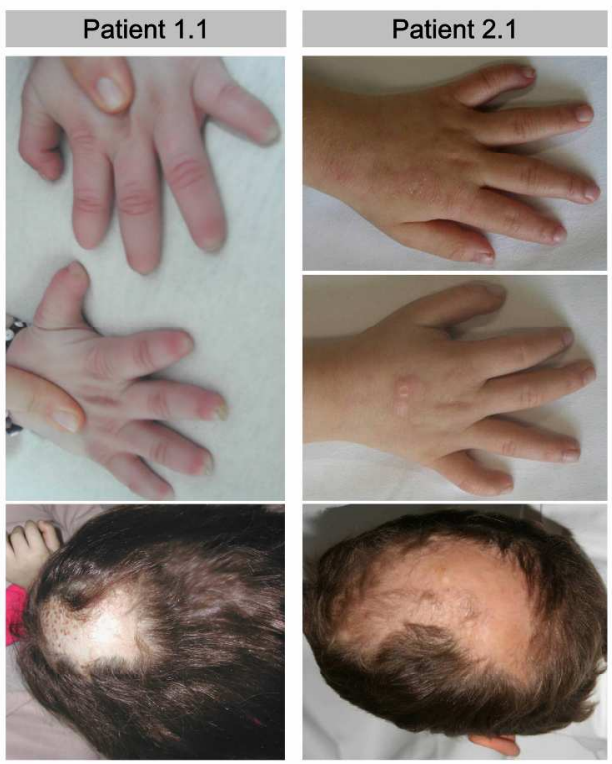

C
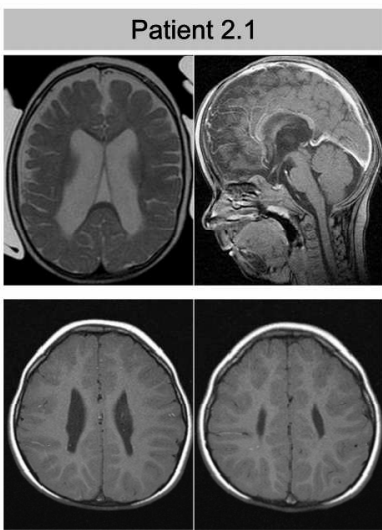

Patient 5.1
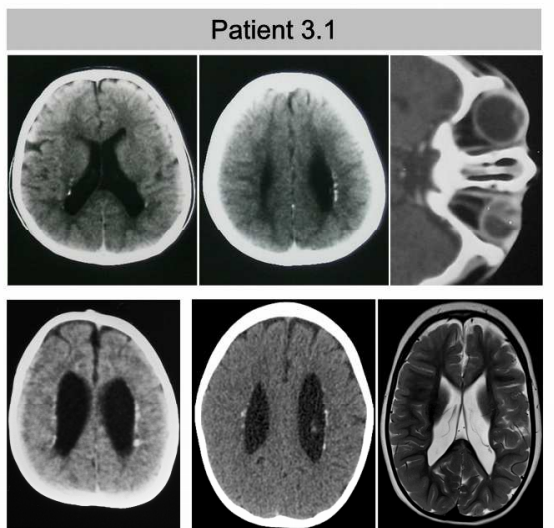

Patient 6.1

Patient 3.1

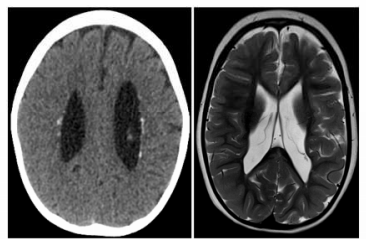

Patient 10.1

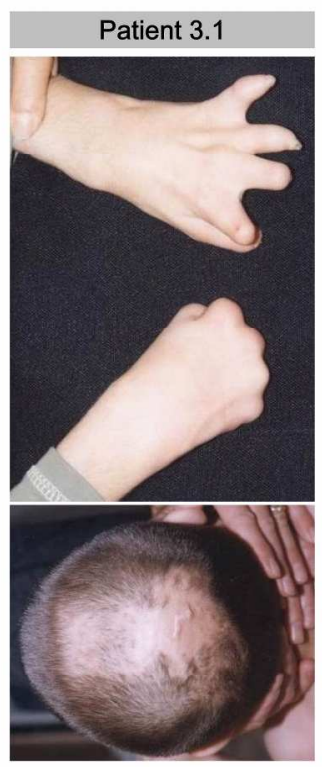

(A) DOCK6 protein with known functional domains and distribution of mutations.

(B) Clinical photographs of three DOCK6-positive individuals with AOS from this cohort showing areas of alopecia on the vertex resulting from aplasia cutis congenita and terminal defects of the digits of varying severity.

(C) Brain imaging of AOS patients with DOCK6 mutations. [RGB color]

$195 \times 299 \mathrm{~mm}(300 \times 300 \mathrm{DPI})$ 


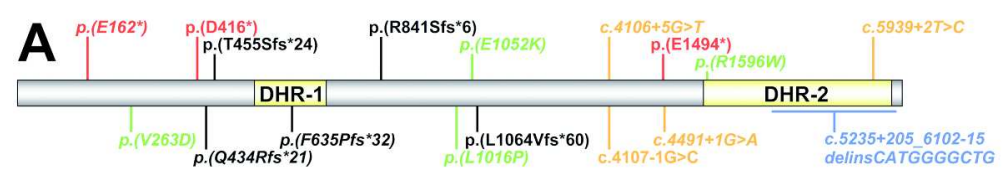

B
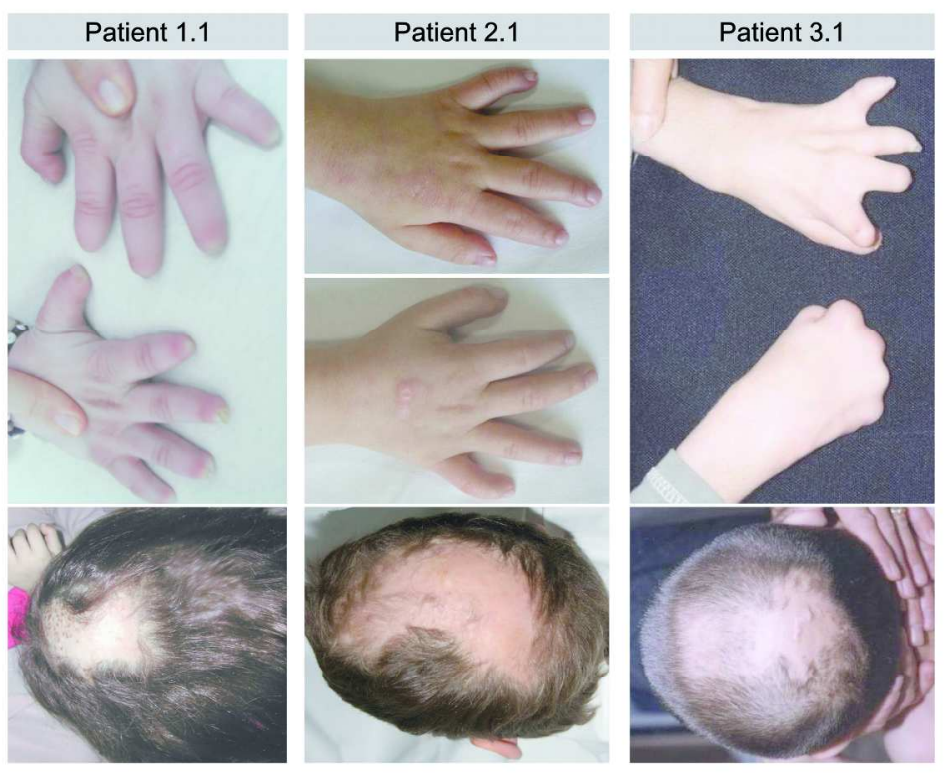

C
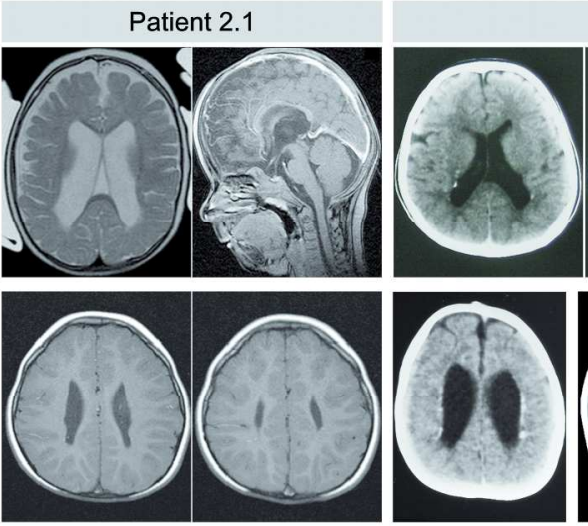

Patient 3.1

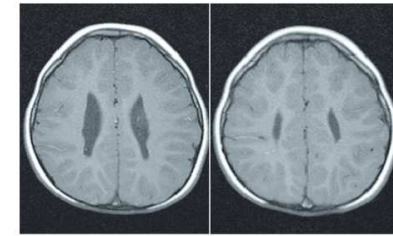

Patient 5.1

Patient 6.1

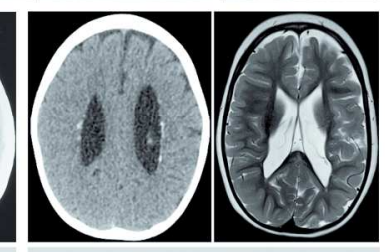

Patient 10.1

(A) DOCK6 protein with known functional domains and distribution of mutations.

(B) Clinical photographs of three DOCK6-positive individuals with AOS from this cohort showing areas of alopecia on the vertex resulting from aplasia cutis congenita and terminal defects of the digits of varying severity.

(C) Brain imaging of AOS patients with DOCK6 mutations.

[CMYK color]

$195 \times 299 \mathrm{~mm}(300 \times 300$ DPI $)$ 
Table 1: Mutation and phenotype data of DOCK6-positive individuals from this cohort (families 1-10) compared to previously published cases (families 11-15).

\begin{tabular}{|c|c|c|c|c|c|c|c|c|c|c|c|c|c|c|c|c|}
\hline 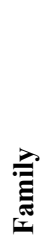 & 莺 & & Uूँ & $\stackrel{80}{2}$ & 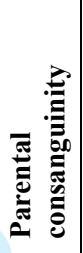 & 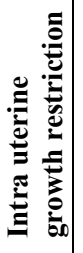 & 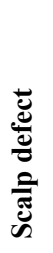 & 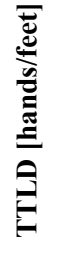 & 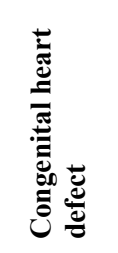 & 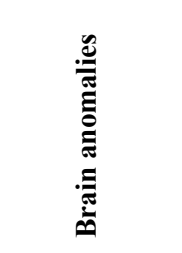 & 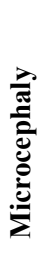 & 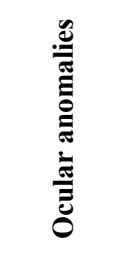 & 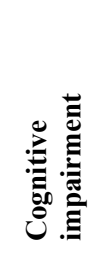 & $\begin{array}{l}\overrightarrow{00} \\
\frac{0}{0} \\
\overline{0} \\
\overline{0} \\
z\end{array}$ & 预 & 苞 \\
\hline 1 & 1.1 & [p.L1016P] + [p.L1016P] & $\mathrm{F}$ & $5 y$ & + & na & + & $+/+$ & na & na & + & $\begin{array}{l}\text { MO, RD, } \\
\text { VO, ACA }\end{array}$ & DD & SE & high palate & - \\
\hline 2 & 2.1 & {$[\mathrm{p} . \mathrm{T} 455 \mathrm{Sfs} * 24]+[\mathrm{c} .4491+1 \mathrm{G}>\mathrm{A}]$} & M & $10 \mathrm{y}$ & - & - & + & $+/+$ & na & $\begin{array}{l}\mathrm{VD} / \mathrm{BA} \\
\mathrm{CCH}\end{array}$ & + & NS & sev ID & $\begin{array}{l}\text { SE, } \\
\text { CP }\end{array}$ & $\begin{array}{c}\text { CMTC, } \\
\text { single umbilical artery, } \\
\text { cryptorchidism }\end{array}$ & - \\
\hline 3 & 3.1 & [p.Q434Rfs*21] + [p.Q434Rfs*21] & $\mathrm{M}$ & $20 y$ & + & + & + & $+/+$ & - & VD/BA, PVL & + & $\begin{array}{l}\mathrm{MO}, \mathrm{RD} \\
\mathrm{ACA}\end{array}$ & sev ID & $\begin{array}{l}\mathrm{SE}, \\
\mathrm{CP}\end{array}$ & $\begin{array}{c}\text { CMTC, } \\
\text { abdominal skin defect }\end{array}$ & - \\
\hline 4 & 4.1 & [p.R1596W] + [p.R1596W] & $\mathrm{F}$ & $3 \mathrm{~m}$ & + & - & + & $+/+$ & PDA & $\mathrm{VD} / \mathrm{BA}$ & + & MO & na & - & knee dislocation & - \\
\hline 5 & 5.1 & [p.E1052K] + [p.E1052K] & M & $9 y$ & + & + & + & $+/+$ & - & $\begin{array}{c}\mathrm{VD} / \mathrm{BA} \\
\mathrm{CCH}, \mathrm{PVL}\end{array}$ & + & $\mathrm{MO}, \mathrm{RD}$ & $\bmod I D$ & $\mathrm{SE}$ & cryptorchidism & 1 \\
\hline \multirow{2}{*}{6} & 6.1 & {$[\mathrm{p} . \mathrm{V} 263 \mathrm{D}]+[\mathrm{c} .5939+2 \mathrm{~T}>\mathrm{C}]$} & $\mathrm{F}$ & na & - & - & + & $+/+$ & VSD & VD/BA, PVL & + & $\begin{array}{l}\mathrm{MO}, \mathrm{RD} \\
\mathrm{VO}\end{array}$ & sev ID & $\begin{array}{l}\text { SE, } \\
\mathrm{CP}\end{array}$ & $\begin{array}{l}\text { abdominal skin defects, } \\
\text { absence of right patella }\end{array}$ & 2 \\
\hline & 6.2 & {$[\mathrm{p} . \mathrm{V} 263 \mathrm{D}]+[\mathrm{c} .5939+2 \mathrm{~T}>\mathrm{C}]^{\mathrm{a}}$} & M & $1 \mathrm{w}^{\dagger}$ & - & + & + & $+/+$ & na & $\begin{array}{c}\mathrm{VD} / \mathrm{BA} \\
\mathrm{CCH}\end{array}$ & na & $\mathrm{RD}$ & na & na & $\begin{array}{l}\text { abdominal skin defect, } \\
\text { patella fixed to skin }\end{array}$ & 2 \\
\hline \multirow{2}{*}{7} & 7.1 & {$[\mathrm{p} . \mathrm{F} 635 \mathrm{Pfs} * 32]+[\mathrm{c} .4106+5 \mathrm{G}>\mathrm{T}]$} & $\mathrm{F}$ & $7 y$ & - & - & + & $+/+$ & - & NS & + & NS & sev ID & $\mathrm{SE}$ & abdominal skin defect & - \\
\hline & 7.2 & {$[\mathrm{p} . \mathrm{F} 635 \mathrm{Pfs} * 32]+[\mathrm{c} .4106+5 \mathrm{G}>\mathrm{T}]$} & $\mathrm{M}$ & $8 \mathrm{y}$ & - & + & - & $-/+$ & TAPVD & na & na & NS & mild ID & - & hypothyroidism & - \\
\hline 8 & 8.1 & {$[$ p.E162*] $+[$ p.E162*] } & $\mathrm{F}$ & na & + & na & + & $+/+$ & na & na & na & na & na & na & & - \\
\hline 9 & 9.1 & $\begin{array}{c}{\left[\mathrm{c} .5235+205 \_6102-15 \text { delins } 10\right]+} \\
{\left[\mathrm{c} .5235+205 \_6102-15 \text { delins } 10\right]}\end{array}$ & $\mathrm{F}$ & $7 y$ & + & - & + & $+/+$ & na & PVL & na & na & na & na & & - \\
\hline 10 & 10.1 & [p.R841Sfs*6] + [p.R841Sfs*6] & $\mathrm{F}$ & na & + & - & + & $+/+$ & na & $\begin{array}{l}\mathrm{VD} / \mathrm{BA}, \\
\mathrm{CCH}, \mathrm{PVL}\end{array}$ & + & na & na & SE & & - \\
\hline 11 & 11.1 & [p.T455Sfs*24] + [p.T455Sfs*24] & $\mathrm{F}$ & $11 \mathrm{~m}$ & + & na & + & $+/+$ & - & VD/BA, PVL & + & OA & sev ID & $\begin{array}{l}\text { SE, } \\
\text { CP }\end{array}$ & & 3 \\
\hline 12 & 12.1 & [p.D416*] + [p.D416*] & $\mathrm{F}$ & $3.5 y$ & + & na & + & $+/+$ & - & na & + & - & DD & na & & 3 \\
\hline \multirow{2}{*}{13} & 13.1 & [p.R841Sfs*6] + [p.R841Sfs*6] & $\mathrm{M}$ & $1 \mathrm{y}$ & + & na & + & $+/+$ & AVD & VD/BA, PVL & na & - & na & na & abdominal skin defect & 4 \\
\hline & 13.2 & [p.R841Sfs*6] + [p.R841Sfs*6] & $\mathrm{F}$ & na & + & na & + & $+/+$ & na & VD/BA, PVL & na & na & na & $\mathrm{SE}$ & gastroschisis & 4 \\
\hline 14 & 14.1 & {$[\mathrm{c} .4107-1 \mathrm{G}>\mathrm{C}]+[\mathrm{c} .4107-1 \mathrm{G}>\mathrm{C}]$} & $\mathrm{F}$ & $2 y$ & + & na & + & $+/+$ & na & PVL, PA & na & $\mathrm{OA}$ & na & $\mathrm{SE}$ & & 4 \\
\hline 15 & 15.1 & [p.L1064Vfs*60] + [p.E1494*] & $\mathrm{F}$ & $2 y$ & - & + & + & $+/+$ & $\begin{array}{l}\text { TOF, } \\
\text { PLSVC }\end{array}$ & PVL, PE & + & $\mathrm{RD}$ & sev ID & SE & $\begin{array}{l}\text { placental vasculopathy, } \\
\text { neonatal thrombocytopenia, } \\
\text { small bowel infarction }\end{array}$ & 5 \\
\hline
\end{tabular}


${ }^{a}$ Genotype was not directly confirmed as patient is deceased but is assumed to be the same as in affected sibling.

F, female; M, male; y, year(s); m, month(s); w, weeks(s); ${ }^{\dagger}$, deceased; na, no data available; +, present; -, not present; TTLD, terminal transverse limb defects; PDA, patent ductus arteriosus; VSD, ventricular septal defect; TAPVD, total anomalous pulmonary venous connection; AVD, aortic valve dysplasia; TOF, tetralogy of Fallot; PLSVC, persistent left superior vena cava; VD/BA, ventricular dilatation / brain atrophy; CCH, corpus callosum hypoplasia/atrophy; PVL, periventricular lesions (calcification, gliosis); NS, abnormality present, not further specified; PA, pachygyria; $\mathrm{PE}$, porencephaly; MO, microphthalmia; RD, retinal detachment; VO, vitreous opacities/membranes; ACA, anterior chamber abnormality; OA, optic atrophy; DD, developmental delay; ID, intellectual disability; sev, severe; mod, moderate; SE, seizures / epilepsy; CP, cerebral palsy / spasticity; CMTC, cutis marmorata telangiectatica congenita. References: (1) Prothero et al. (2007); (2) Orstavik et al. (1995); (3) Shaheen et al. (2011); (4) Shaheen et al. (2013); (5) Lehman et al. (2014). 


\title{
DOCK6 Mutations are Responsible for a Distinct Autosomal Recessive Variant of Adams-Oliver Syndrome Associated with Brain and Eye Anomalies
}

\begin{abstract}
Maja Sukalo $^{1 \dagger^{*}}$, Felix Tilsen ${ }^{1 \dagger}$, Hülya Kayserili ${ }^{2}$, Dietmar Müller ${ }^{3}$, Beyhan Tüysüz ${ }^{4}$, Deborah M. Ruddy ${ }^{5}$, Emma Wakeling, ${ }^{6}$, Karen Helene Ørstavik ${ }^{7}$, Katie M. Snape ${ }^{8}$, Richard Trembath $^{5,9}$, Maryse De Smedt ${ }^{10}$, Nathalie van der $\mathrm{Aa}^{11}$, Martin Skalej ${ }^{12}$, Stefan Mundlos ${ }^{13}$, Wim Wuyts ${ }^{11,14 \#, \text { Laura Southgate }}{ }^{9,15 \#}$, Martin Zenker ${ }^{1 \#}$

${ }^{1}$ Institute of Human Genetics, University Hospital Magdeburg, Magdeburg, Germany. ${ }^{2}$ Medical Genetics Department, Istanbul Medical Faculty, Istanbul, Turkey. ${ }^{3}$ Institut für Medizinische Genetik, Klinikum Chemnitz, Chemnitz, Germany. ${ }^{4}$ Department of Pediatric Genetics, Istanbul University, Istanbul, Turkey. ${ }^{5}$ Department of Clinical Genetics, Guy's Hospital, London, UK. ${ }^{6}$ North West Thames Regional Genetics Service, North West London Hospitals NHS Trust, Harrow, UK. ${ }^{7}$ Department of Medical Genetics, Oslo University Hospital, Oslo, Norway. ${ }^{8}$ Department of Clinical Genetics, St George's Healthcare NHS Trust, London, UK. ${ }^{9}$ Barts and The London School of Medicine and Dentistry, Queen Mary University of London, London, UK. ${ }^{10}$ Department of Medical Genetics, Leuven University Hospital, Leuven, Belgium. ${ }^{11}$ Department of Medical Genetics, Antwerp University Hospital, Antwerp, Belgium. ${ }^{12}$ Institute of Neuroradiology, Otto von Guericke University Magdeburg, Magdeburg, Germany. ${ }^{13}$ Institute for Medical and Human Genetics Charité, Universitätsmedizin Berlin and Max Planck Institute for Molecular Genetics Berlin, Berlin, Germany. ${ }^{14}$ Department of Medical Genetics, University of Antwerp, Antwerp, Belgium. ${ }^{15}$ Division of Genetics and Molecular Medicine, King's College London, London, UK . † These authors contributed equally as first authors. \# These authors contributed equally as senior authors.
\end{abstract}

\section{Supp. Material and Methods}

We designed oligonucleotide primers for each of the 48 exons of DOCK6 using the Primer3 software version 4.0.0 (http://primer3.ut.ee/) [Untergrasser et al., 2012]. Primer sequences and PCR conditions are available upon request. Sequencing was carried out using the BigDye Terminator Cycle Sequencing Kit v3.1 on an ABI 3500xl automated capillary sequencer (Applied Biosystems, Cheshire, UK). Obtained sequences were compared with the reference sequence (NM_020812.3) using the Sequence Pilot software v4.0.1 (JSI Medical Systems GmbH, Kippenheim, Germany). Pathogenicity of all observed sequence variants was assessed using various online prediction tools. For splice site prediction we utilized the following bioinformatic tools:

- BDGP (Berkeley Drosophila Genome Project)

last updated 28 July 2014, Human or other, minimum scores for splice sites: 0.1

http://www.fruitfly.org/seq tools/splice.html [Reese et al., 1997]

- NetGene2

Version 2.4, Human

http://www.cbs.dtu.dk/services/NetGene2/ [Brunak et al., 1991]

Missense mutations were rated using the following:

- PolyPhen-2 (Polymorphism Phenotyping v2)

Version 2.2.2, NP_065863.2

http://genetics.bwh.harvard.edu/pph2/ [Adzhubei et al., 2010]

- SIFT Human Protein (Sorting Intolerant From Tolerant)

page last modified: August 2011, Ensembl 63, ENSP00000294618

http://sift.jcvi.org/www/SIFT_enst_submit.html [Ng and Henikoff, 2003]

John Wiley \& Sons, Inc. 
Sukalo et al. (2015), Human Mutation, Supporting Material

- MutPred (Mutation Prediction)

last modified 02 Feb 2014, NP_065863.2

http://mutpred.mutdb.org [Li et al., 2009]

- GERP (Genomic Evolutionary Rate Profiling)

hg19,

http://mendel.stanford.edu/SidowLab/downloads/gerp/index.html [Cooper et al., 2005]

All variants were checked regarding their appearance/frequency in EVS (Exome Variant Server, Gene ID: 57572, GRCh37, http://evs.gs.washington.edu/EVS/, [Exome Variant Server, 2015]) and TGP (1000 Genomes Project, http://www.1000genomes.org/home, [1000 Genomes Project Consortium et al., 2010]). Protein conservation across species was checked by Standard Protein BLAST (Basic Local Alignment Search Tool, Database: Reference proteins (refseq_protein), Algorithm: blastp (protein-protein BLAST), http://blast.ncbi.nlm.nih.gov/Blast.cgi, [Altschul et al., 1990]). Segregation of the variants across family members was checked if appropriate material was available. Designation of mutations follows the guidelines of the Human Genome Variation Society (last modified March 2014; http://www.hgvs.org/mutnomen/) [den Dunnen and Antonarakis, 2000] and was verified by Mutalyzer (Version 2.0 beta-24; https://mutalyzer.nl/) [Wildeman et al., 2008].

A focused MLPA assay including probes for DOCK6 exons 40 through 48 was developed (probe sequences available upon request) for copy number determination of the terminal DOCK6 exons in a family where PCR amplification of exons 42 to 48 failed in the index patient.

We have established a collection of all mutations and selected unclassified variants in the DOCK6 gene (http://databases.lovd.nl/shared/variants/DOCK6) at the Leiden Open Variation Database (LOVD, version 3.0) [Fokkema et al., 2011], as well as all available phenotype data of patients that were designated as AOS2 both clinically and genotypically (http://databases.lovd.nl/shared/individuals/DOCK6). To date, the database contains 17 different DOCK6 mutations and phenotype data from 18 individuals.

Supp. Figure S1: Pedigrees and electropherograms of DOCK6-positive AOS patients and their families.

\section{Family 1}

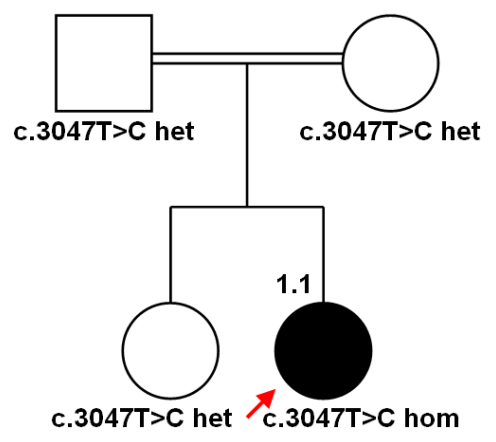

c.3047T>C / p.(Leu1016Pro)

Val Phe Ser Leu Val Arg Ala GTC TTC AGC CTG GTC CGG GCC

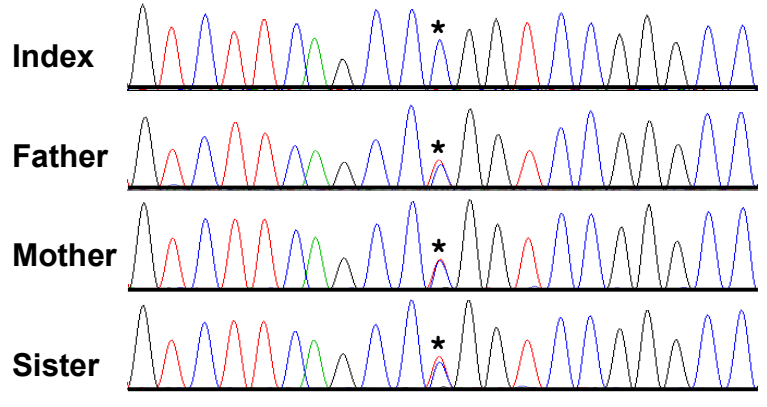


Sukalo et al. (2015), Human Mutation, Supporting Material

\section{Family 2}

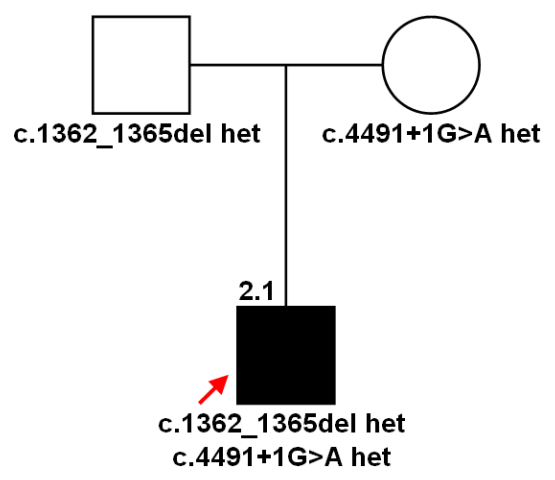

RNA analysis c.1362_1365del / p.(Thr455Serfs*24)

Pro Ala Thr Leu Thr Val Thr CCA GCC ACG CTA ACT GTC ACA

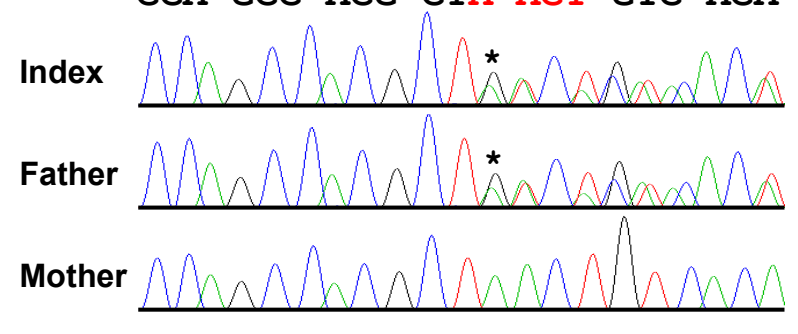

\section{c. $4491+1 G>A$}

Ile Gly His +1

ATC GGC CAC gtgagaggggg

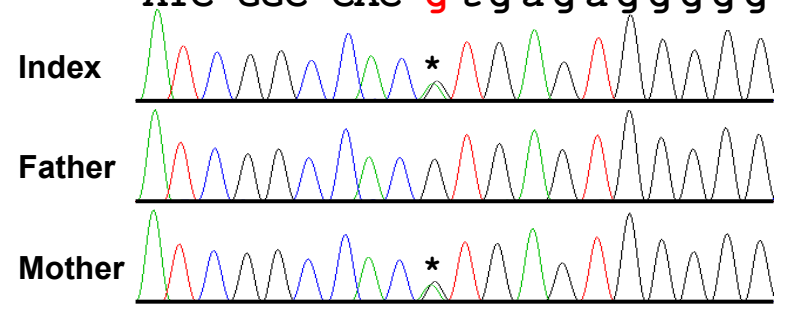

Ex 34

T G T T C CAAGT T C C C G GA G

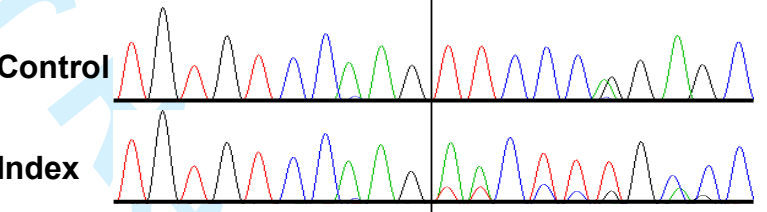

A A C T T T G C C C

\section{Family 3}

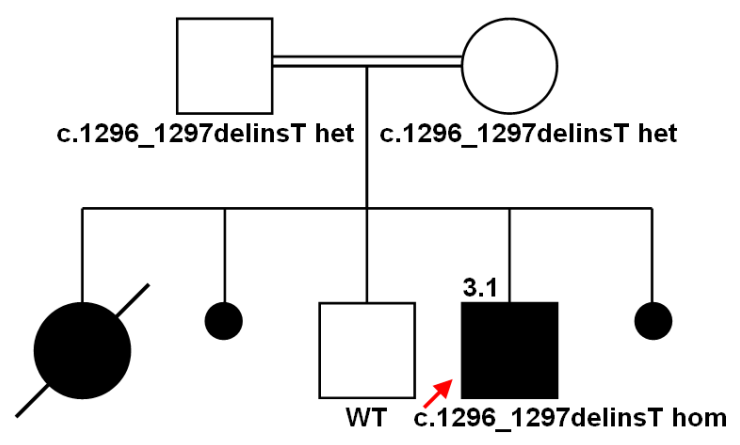

c.1296_1297delinsT / p.(GIn434Argfs*21) Arg Arg Arg Gly Pro Gln Asp Arg
CGC CGT CGG GGG CCC CAG GAC CGG index WMWWWMWMWMM

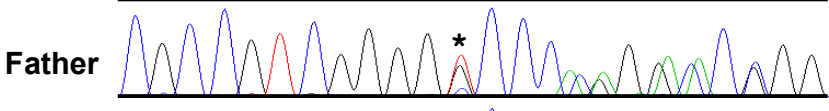

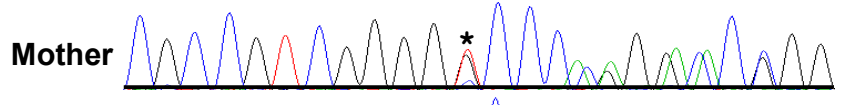

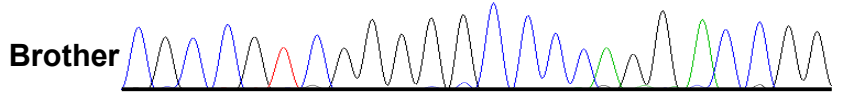




\section{Family 4}

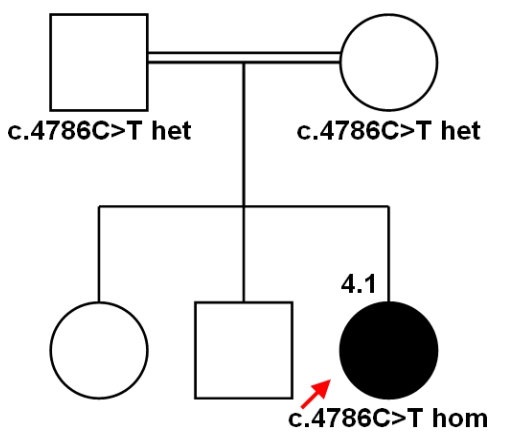

c.4786C > T / p.(Arg1596Trp)

Pro Asp Leu Arg Leu Thr Trp

CCG GAC CTT CGG CTG ACC TGG

Index

Father

Mother

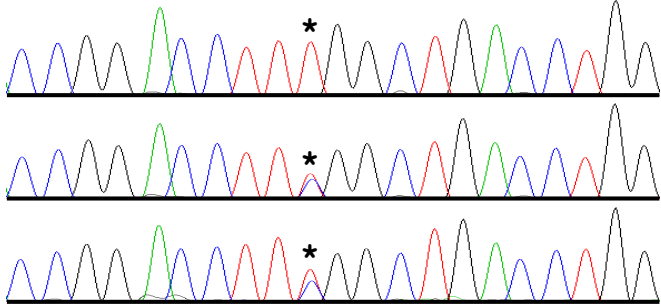

\section{Family 5}

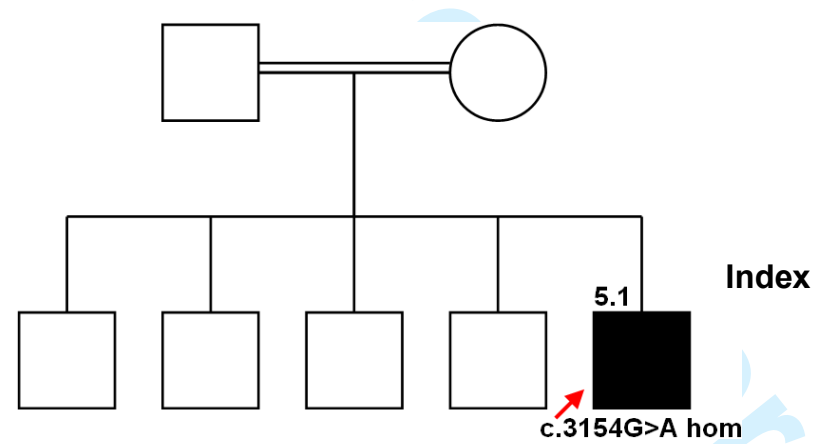

\section{c.3154G>A / p.(Glu1052Lys)}

Cys Ser His Glu His Tyr Val

TGC AGC CAC GAG CAC TAC GTG

\section{Family 6}

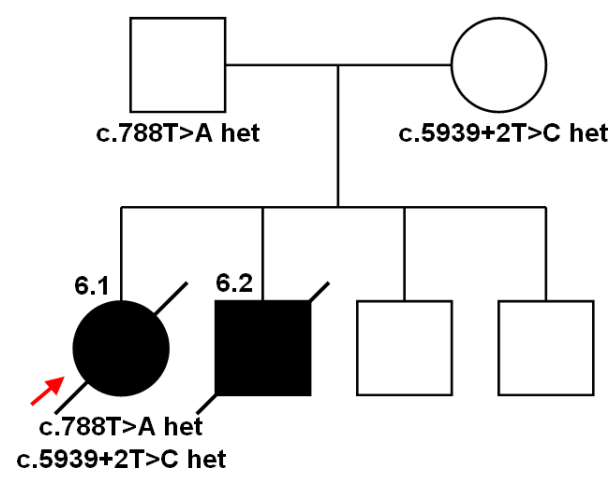

\section{c.788T >A / p.(Val263Asp)}

Arg Ile Leu Val Lys Cys Leu AGG ATC TTG GTC AAG TGT CTG

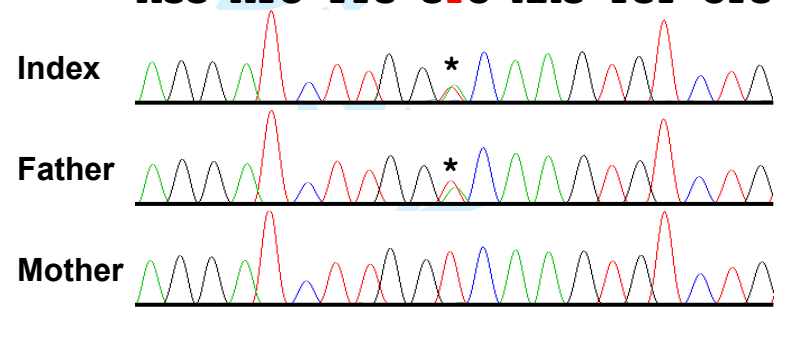

\section{c. $5939+2 \mathrm{~T}>\mathrm{C}$}

Cys Lys ...+2

TGC AAG AÀ gtaggcgca a

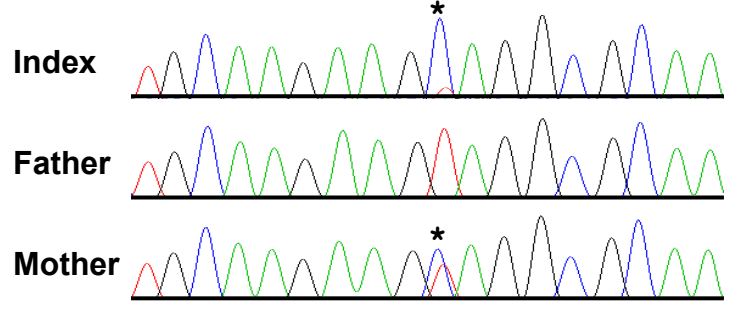


Sukalo et al. (2015), Human Mutation, Supporting Material

1

2

3

4

5

6

7

8

9

10

\section{Family 7}

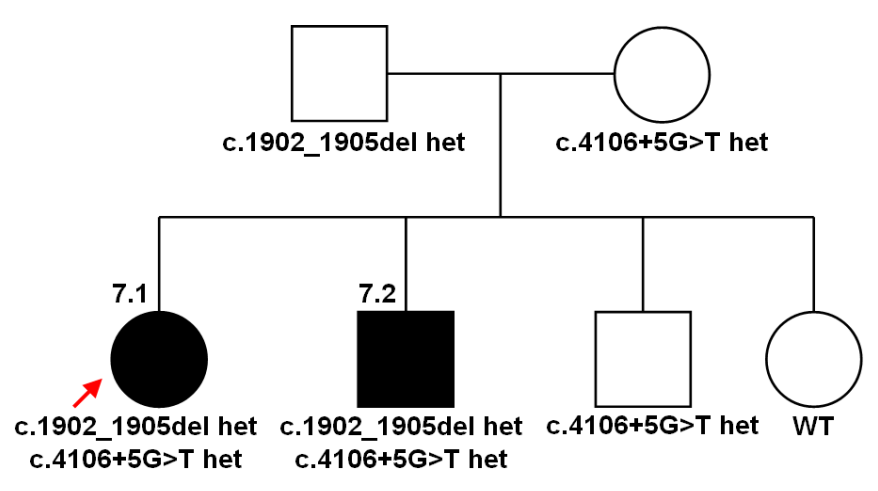

c.1902_1905del / p.(Phe635Profs*32)

His His Leu Leu Phe Thr Phe CAT CAC CTG CTG TTC ACC TTC

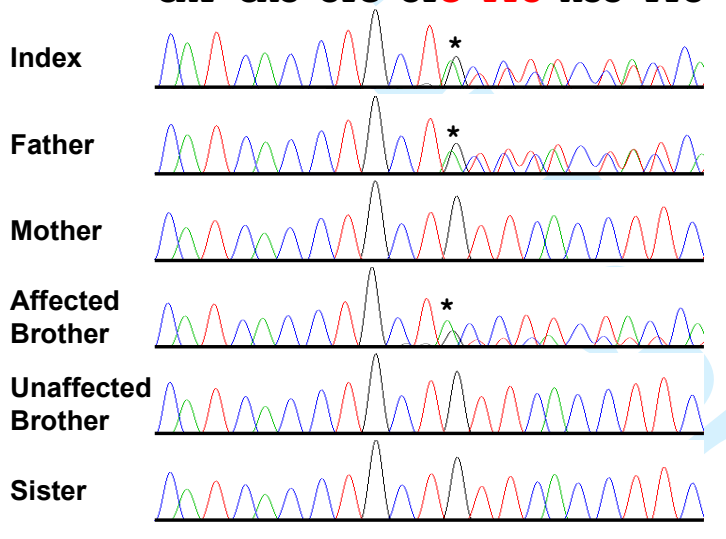

\section{c. $4106+5 \mathrm{G}>\mathrm{T}$}

Val Asp ... +5 GTG GAC $\dot{A} \ddot{A}$ gtaggtgtggg Index Father Mother

Affected Brother

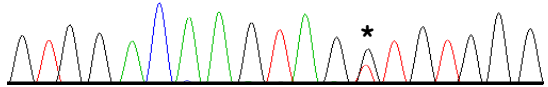

Unaffected Brother

Sister
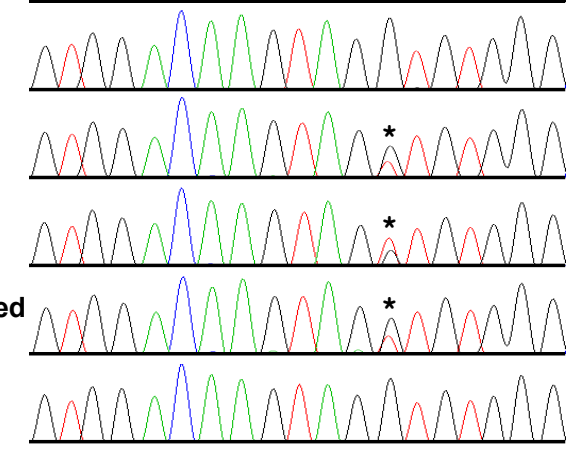

\section{Family 8}

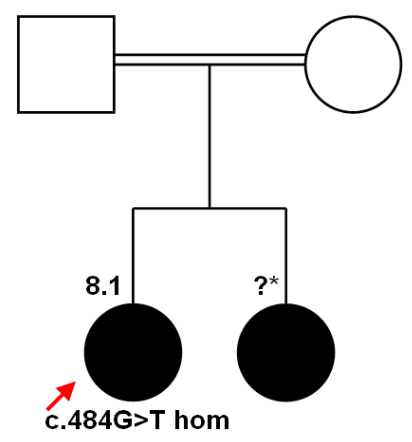

\section{c.484G>T / p.(Glu162*)}

Ser Gly Asp Glu Arg Ser Gly TCT GGÄ GAC GAG AGG TCC GGC Index

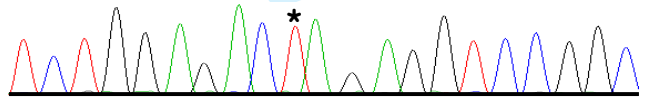




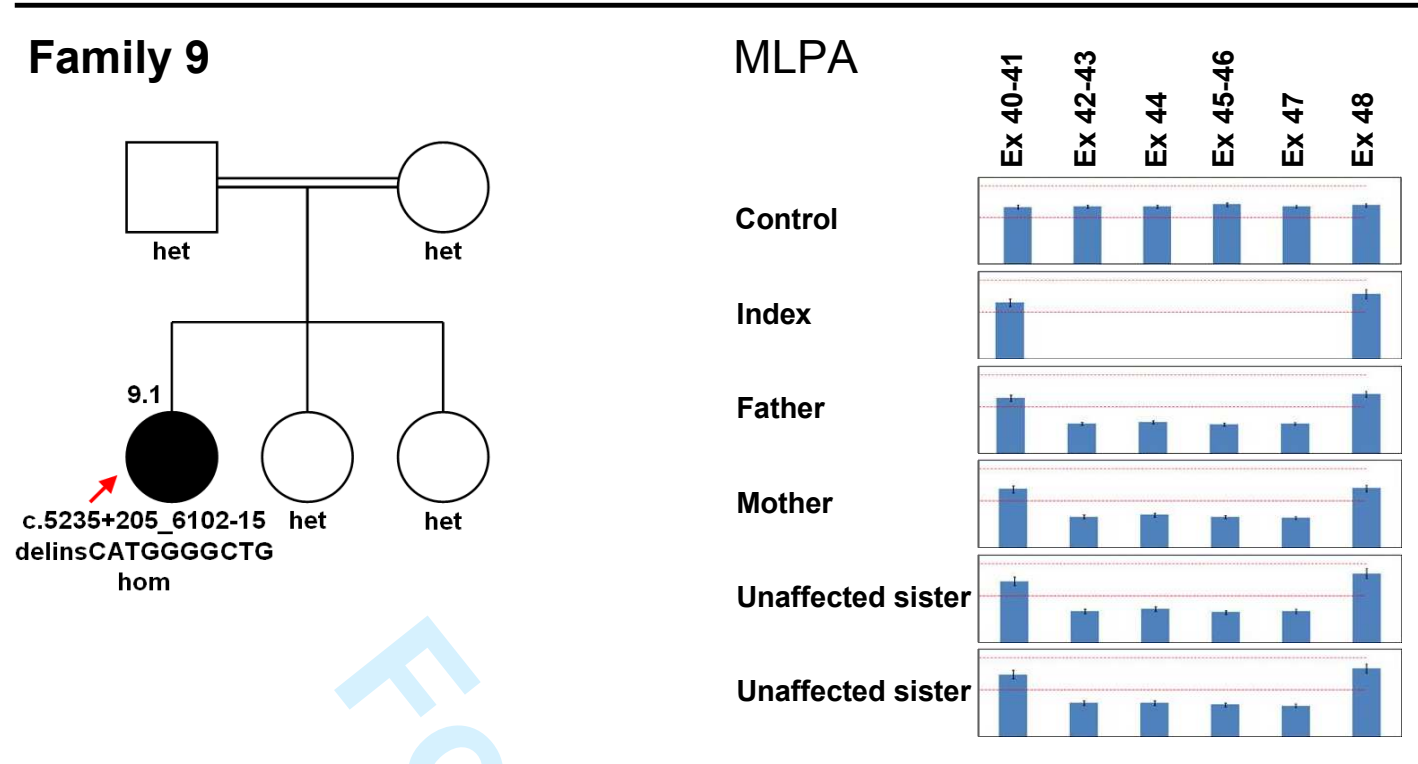

\section{c.5235+205_6102-15delinsCATGGGGCTG hom}

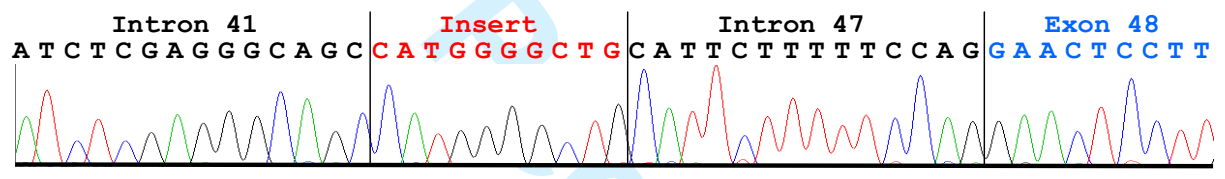

\section{Family 10}

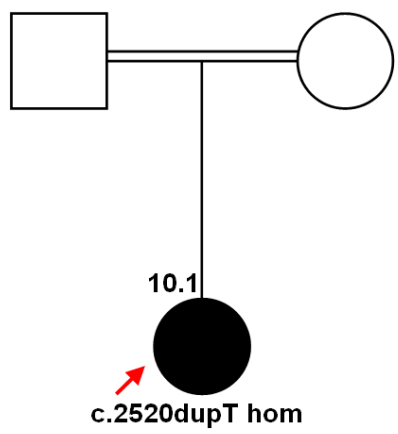

C.2520dupT / p.(Arg841Serfs*6)

Tyr Ala Phe Arg Leu Pro Gly TAC GCC TTT CGC CTT CCT GGC

Index

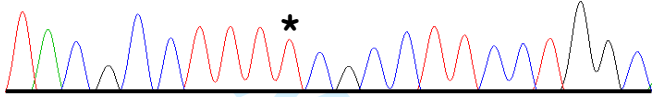

Pedigrees representing DOCK6 mutation positive families. Affected individuals are indicated by filled symbols. All available genotype data is added and sequence electropherograms are shown. Family 2: RNA analysis is additionally displayed. Family 6: in the index patient the wild type allele is drastically under-represented regarding the heterozygous c.5939+2T $>\mathrm{C}$ splice site mutation. We assume this to be caused by a technical artefact due to very poor DNA quality. Family 9: MLPA results (multiplex ligation-dependent probe amplification) are shown.

hom, homozygous; het, heterozygous; WT, wild type; ?* patient not listed in table 1 due to lack of clinical data and not genetically analyzed due to lack of adequate material. 
Sukalo et al. (2015), Human Mutation, Supporting Material

Supp. Table S1: Mutations in the DOCK6 gene causing Adams-Oliver syndrome.

\begin{tabular}{|c|c|c|c|c|c|c|}
\hline Location & Nucleotide Alteration & Predicted effect $^{\mathrm{a}}$ & $\begin{array}{l}\text { Family } \\
\text { ID }\end{array}$ & EVS & $\begin{array}{l}\text { MAF } \\
\text { (TGP) }\end{array}$ & Reference(s) \\
\hline Exon 05 & c. $484 \mathrm{G}>\mathrm{T}$ & p.(Glu162*) & 8 & - & - & this paper \\
\hline Exon 07 & c. $788 \mathrm{~T}>\mathrm{A}$ & p.(Val263Asp) & 6 & - & - & this paper \\
\hline Exon 11 & c.1245dupT & p.(Asp416*) & 12 & - & - & Shaheen et al. [2011] \\
\hline Exon 12 & c.1296_1297delinsT & p. $(\mathrm{Gln} 434 \mathrm{Argfs} * 21)$ & 3 & - & - & this paper \\
\hline Exon 12 & c. $1362 \_1365 \mathrm{del}$ & p.(Thr455Serfs*24) & 2,11 & $0.26 \%$ & - & this paper + Shaheen et al. [2011] \\
\hline Exon 17 & c.1902_1905del & p.(Phe635Profs*32) & 7 & - & - & this paper \\
\hline Exon 21 & c.2520dupT & p.(Arg841Serfs*6) & 10,13 & - & - & this paper + Shaheen et al. [2013] \\
\hline Exon 25 & c. $3047 \mathrm{~T}>\mathrm{C}$ & p.(Leu1016Pro) & 1 & - & - & this paper \\
\hline Exon 26 & c. $3154 \mathrm{G}>\mathrm{A}$ & p.(Glu1052Lys) & 5 & - & - & this paper \\
\hline Exon 26 & c.3190_3191del & p.(Leu1064Valfs*60) & 15 & $0.02 \%$ & - & Lehman et al. [2014] \\
\hline Intron 32 & c. $4106+5 \mathrm{G}>\mathrm{T}$ & r.spl.? p.? & 7 & - & - & this paper \\
\hline Intron 32 & c. $4107-1 \mathrm{G}>\mathrm{C}$ & p.Thr1370Metfs $* 19$ & 14 & - & - & Shaheen et al. [2013] \\
\hline Exon 35 & c. $4480 \mathrm{G}>\mathrm{T}$ & p.(Glu1494*) & 15 & - & - & Lehman et al. [2014] \\
\hline Intron 35 & c. $4491+1 \mathrm{G}>\mathrm{A}$ & r.spl.? p.? & 2 & - & - & this paper \\
\hline Exon 38 & c. $4786 \mathrm{C}>\mathrm{T}$ & p.(Arg1596Trp) & 4 & - & - & this paper \\
\hline $\begin{array}{l}\text { Intron } 41- \\
\text { Intron } 47\end{array}$ & $\begin{array}{l}\text { c.5235+205_6102-15 } \\
\text { delinsCATGGGGCTG }\end{array}$ & p. $?^{\mathrm{b}}$ & 9 & - & - & this paper \\
\hline Intron 46 & c. $.5939+2 \mathrm{~T}>\mathrm{C}^{\mathrm{c}}$ & r.spl.? p.? & 6 & $0.02 \%$ & - & this paper \\
\hline
\end{tabular}

${ }^{a}$ Italic letters indicate that the effect of splicing mutations was demonstrated on the mRNA level.

${ }^{\mathrm{b}}$ MLPA analysis revealed deletion of exons 42 to 47.

${ }^{c}$ This alteration is also listed in dbSNP (rs201387914) with unknown pathogenicity and frequency. Online tools predict destruction of the donor splice site.

Mutation nomenclature refers to GenBank reference sequence NM_020812.3. Nucleotide numbering reflects cDNA numbering with +1 corresponding to the A of the ATG translation initiation codon in the reference sequence, according to journal guidelines (www.hgvs.org/mutnomen). The initiation codon is codon 1.

EVS (Exome Variant Server): frequency of alterations was calculated according to the total allele count; MAF (minor allele frequency); TGP (1000 Genomes Project): no entries for these alterations. 
Sukalo et al. (2015), Human Mutation, Supporting Material

Supp. Table S2: Prediction of pathogenicity and conservation of DOCK6 missense mutations.

\begin{tabular}{|c|c|c|c|c|c|c|c|c|}
\hline $\begin{array}{l}\text { Nucleotide } \\
\text { alteration }\end{array}$ & $\begin{array}{c}\text { Predicted } \\
\text { effect }\end{array}$ & $\begin{array}{c}\text { PolyPhen-2 } \\
\text { HumVar } \\
\text { [sensitivity/specificity] }\end{array}$ & $\begin{array}{c}\text { SIFT } \\
\text { [score/median } \\
\text { information content] }\end{array}$ & MutPred & GERP & \multicolumn{3}{|c|}{ BLAST Alignment } \\
\hline c. $788 \mathrm{~T}>\mathrm{A}$ & p.V263D & $\begin{array}{c}\text { probably damaging } \\
(0.998) \\
------- \\
0.18 / 0.98\end{array}$ & $\begin{array}{c}\text { damaging } \\
-\mathbf{-}-\mathbf{-}-\mathbf{-}-\boldsymbol{-} \\
0.00 / 2.75\end{array}$ & 0.735 & 5.05 & $\begin{array}{l}\text { Human } \\
\text { Mmulatta } \\
\text { Mmusculus } \\
\text { Trubripes } \\
\text { Drerio } \\
\text { Dmelanogaster } \\
\text { Celegans } \\
\text { Xtropicalis }\end{array}$ & $\begin{array}{l}263 \\
249 \\
263 \\
266 \\
263 \\
271 \\
261 \\
264\end{array}$ & 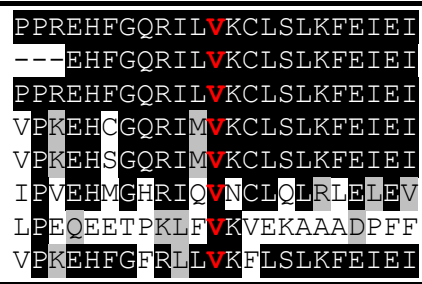 \\
\hline c. $3047 \mathrm{~T}>\mathrm{C}$ & p.L1016P & $\begin{array}{c}\text { probably damaging } \\
(0.977) \\
0.58 / 0.94\end{array}$ & $\begin{array}{c}\text { damaging } \\
-\mathbf{-}-\mathbf{-}-\mathbf{-} \\
0.00 / 2.71\end{array}$ & 0.756 & 4.84 & $\begin{array}{l}\text { Human } \\
\text { Mmulatta } \\
\text { Mmusculus } \\
\text { Trubripes } \\
\text { Drerio } \\
\text { Dmelanogaster } \\
\text { Celegans } \\
\text { Xtropicalis }\end{array}$ & $\begin{array}{l}1016 \\
1002 \\
1080 \\
1088 \\
1083 \\
1052 \\
1027 \\
1044\end{array}$ & 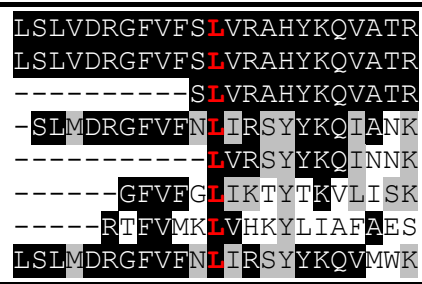 \\
\hline c. $3154 \mathrm{G}>\mathrm{A}$ & p.E1052K & $\begin{array}{c}\text { probably damaging } \\
(0.999) \\
0.09 / 0.99\end{array}$ & $\begin{array}{c}\text { damaging } \\
\mathbf{-}-\mathbf{-}-\mathbf{-}-\mathbf{-}- \\
0.00 / 2.71\end{array}$ & 0.492 & 4.81 & $\begin{array}{l}\text { Human } \\
\text { Mmulatta } \\
\text { Mmusculus } \\
\text { Trubripes } \\
\text { Drerio } \\
\text { Dmelanogaster } \\
\text { Celegans } \\
\text { Xtropicalis }\end{array}$ & $\begin{array}{l}1052 \\
1038 \\
1116 \\
1124 \\
1119 \\
1088 \\
1063 \\
1078\end{array}$ & 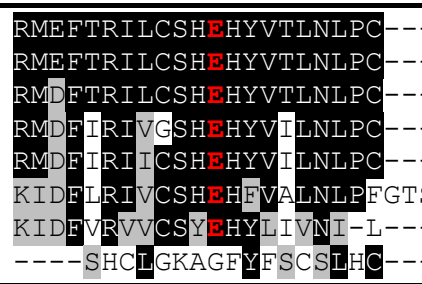 \\
\hline c. $4786 \mathrm{C}>\mathrm{T}$ & p.R1596W & $\begin{array}{c}\text { probably damaging } \\
(0.999) \\
0.09 / 0.99\end{array}$ & $\begin{array}{c}\text { damaging } \\
------- \\
0.00 / 2.71\end{array}$ & 0.715 & 4.99 & $\begin{array}{l}\text { Human } \\
\text { Mmulatta } \\
\text { Mmusculus } \\
\text { Trubripes } \\
\text { Drerio } \\
\text { Dmelanogaster } \\
\text { Celegans } \\
\text { Xtropicalis } \\
\end{array}$ & $\begin{array}{l}1596 \\
1583 \\
1660 \\
1669 \\
1659 \\
1618 \\
1560 \\
1573\end{array}$ & 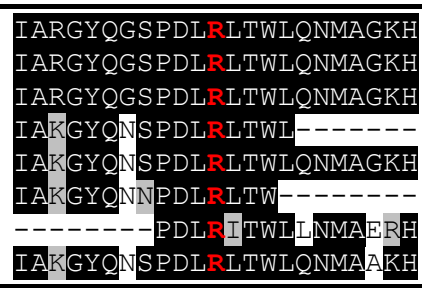 \\
\hline
\end{tabular}


Sukalo et al. (2015), Human Mutation, Supporting Material

Various online prediction tools were used to evaluate mutation effects. PolyPhen-2: score $>0.909$, probably damaging; score $0.447-0.908$, possibly damaging; score $\leq 0.446$, benign; sensitivity: True Positive Rate, the chance that the mutation is classified as damaging when it is indeed damaging; specificity: 1 - False Positive Rate, the chance that the benign mutation is correctly classified as benign [Adzhubei et al., 2013]. SIFT: score $=$ normalized probability that the amino acid change is tolerated; $\leq 0.05$, damaging; $>0.05$, tolerated; median information content: maximum 4.32, indicates complete conservation at this position; minimum 0.00, indicates a position where all 20 amino acids are tolerated; ideally between 2.75 and 3.5 [Ng and Henikoff, 2003]. MutPred: general score; ranges between 1.000 (deleterious mutation) and 0.000 (benign). GERP: ranges from 6.17 (highly conserved amino acid residue) to -12.3 (not conserved). BLAST Alignment: multiple protein alignment of human DOCK6 and its orthologues; numbers indicate position of affected amino acid residue. Black shading indicates identical amino acid residues; grey shading indicates similar residues (according to BLOSUM62 matrix). Human: Homo sapiens, ENSP00000294618.6. Mmulatta: Macaca mulatta, ENSMMUP00000012229.2. Mmusculus: Mus musculus, ENSMUSP00000034728.7. Trubripes: Takifugu rubripes, ENSTRUP00000027209.1. Drerio: Danio rerio, ENSDARP00000077379.4. Dmelanogaster: Drosophila melanogaster, FBpp0077762.3. Celegans: Caenorhabditis elegans, F46H5.4.1. Xtropicalis: Xenopus tropicalis, ENSXETP00000036553.2.

Supp. Table S3: Splice site prediction c. $4106+5 \mathrm{G}>\mathrm{T}$.

\begin{tabular}{|c|c|c|c|}
\hline & \multirow[b]{2}{*}{+5} & \multicolumn{2}{|c|}{ Donor splice site predictions } \\
\hline & & BDGP & NetGene2 \\
\hline Wild type & CGCGTGGACAAgtaggtgtgggcaggagggt & 0.77 & 0.881 \\
\hline Mutant & CGCGTGGACAAgtagttgtgggcaggagggt & 0.15 & 0.341 \\
\hline
\end{tabular}

This donor splice site alteration at position +5 in intron 32 was detected in compound heterozygosity with a frameshift mutation in family 7 . The online tools BDGP (Berkeley Drosophila Genome Project) and NetGene2 predict this nucleotide exchange to impair the regular splice donor site at the border between exon 32 and intron 32 . The indicated probability scores refer to the authentic splice site. 
Sukalo et al. (2015), Human Mutation, Supporting Material

Supp. Table S4: Unclassified variants in the DOCK6 gene.

\begin{tabular}{|c|c|c|c|c|c|}
\hline Location & $\begin{array}{l}\text { Nucleotide } \\
\text { Alteration }^{\mathrm{a}}\end{array}$ & Predicted effect & dbSNP (139) & EVS & $\begin{array}{c}\text { MAF } \\
\text { (TGP) }\end{array}$ \\
\hline Exon 02 & c. $100 \mathrm{C}>\mathrm{G}$ & p.(His34Asp) & rs201065561 & - & $0.0004 / 2$ \\
\hline Exon 09 & c. $885 \mathrm{C}>\mathrm{T}$ & p. $(=)$ & rs146599144 & $0.46 \%$ & $0.0048 / 24$ \\
\hline Exon 12 & c. $1289 \mathrm{G}>\mathrm{A}$ & p.(Arg430His) & rs143655255 & $0.30 \%$ & $0.0028 / 14$ \\
\hline Exon 12 & c. $1358 \mathrm{C}>\mathrm{T}$ & p.(Thr453Met) & - & - & - \\
\hline Exon 13 & c. $1445 \mathrm{C}>\mathrm{T}$ & p.(Pro482Leu) & - & - & - \\
\hline Intron 16 & c. $1833-19 \mathrm{C}>\mathrm{G}$ & r.spl.? p.? & rs188183013 & $0.22 \%$ & $0.0028 / 14$ \\
\hline Exon 19 & c. $2104 \mathrm{G}>\mathrm{A}$ & p.(Gly702Ser) & rs199838752 & $0.08 \%$ & $0.0020 / 10$ \\
\hline Exon 23 & c. $2767 \mathrm{G}>\mathrm{A}$ & p.(Va1923Ile) & rs143194982 & $0.02 \%$ & $0.0002 / 1$ \\
\hline Exon 30 & c. $3873 \mathrm{C}>\mathrm{T}$ & p. $(=)$ & rs200843111 & $0.03 \%$ & - \\
\hline Exon 31 & c. $3913 \mathrm{C}>\mathrm{T}$ & p.(Arg1305Cys) & rs112911897 & $0.70 \%$ & $0.0050 / 25$ \\
\hline Exon 37 & c. $4732 \mathrm{C}>\mathrm{T}$ & p.(Leu1578Phe) & - & - & - \\
\hline Exon 38 & c. $4899 \mathrm{G}>\mathrm{A}$ & p. $(=)$ & rs72985308 & $0.20 \%$ & $0.0010 / 5$ \\
\hline Exon 41 & c. $5229 \mathrm{C}>\mathrm{A}$ & p. $(=)$ & rs56243833 & $0.21 \%$ & $0.0026 / 13$ \\
\hline Exon 44 & c. $5640 \mathrm{C}>\mathrm{T}$ & p. $(=)$ & rs200959822 & $0.11 \%$ & $0.0004 / 2$ \\
\hline Intron 44 & c. $5688+9 \mathrm{G}>\mathrm{C}$ & r.spl.? p.? & - & $0.09 \%$ & $0.0002 / 1$ \\
\hline Intron 45 & c. $5833-16 \mathrm{C}>\mathrm{G}$ & r.spl.? p.? & rs199764395 & $0.05 \%$ & $0.0002 / 1$ \\
\hline
\end{tabular}

Only variants within $20 \mathrm{bp}$ of the exons and MAF $\leq 0.01$ were included. All variants show no alteration of splice site prediction in BDGP and NetGene2. None of these variants appeared as homozygous in TGP (1000 Genomes Project). The numbering for the nucleotide changes are based on cDNA sequence in accordance with the GenBank entry NM_020812.3 (GRCh37). ${ }^{\mathrm{a}}$ For cDNA numbering, +1 corresponds to the A of the ATG translation initiation codon in the reference sequence.

EVS: Exome Variant Server, frequency of alterations was calculated according to the total allele count; MAF: minor allele frequency [frequency of alternative nucleotide / total allele count of alternative nucleotide]. 
Sukalo et al. (2015), Human Mutation, Supporting Material

Supp. Table S5: Prediction of pathogenicity and conservation of DOCK6 unclassified missense variants.

\begin{tabular}{|c|c|c|c|c|c|c|c|c|}
\hline $\begin{array}{l}\text { Nucleotide } \\
\text { alteration }\end{array}$ & $\begin{array}{c}\text { Predicted } \\
\text { effect }\end{array}$ & $\begin{array}{c}\text { PolyPhen-2 } \\
\text { HumVar } \\
\text { [sensitivity/specificity] }\end{array}$ & $\begin{array}{c}\text { SIFT } \\
\text { [Score/Median } \\
\text { information content] }\end{array}$ & MutPred & GERP & \multicolumn{3}{|c|}{ BLAST Alignment } \\
\hline c. $100 \mathrm{C}>\mathrm{G}$ & p.H34D & $\begin{array}{c}\text { benign }(0.017) \\
-\mathbf{-}-\boldsymbol{-}-\boldsymbol{-}-\boldsymbol{-} \\
0.95 / 0.54\end{array}$ & $\begin{array}{c}\text { tolerated } \\
-\boldsymbol{-}-\boldsymbol{-}-\boldsymbol{-}-\boldsymbol{-} \\
0.34 / 2.77\end{array}$ & 0.155 & 1.86 & $\begin{array}{l}\text { Human } \\
\text { Mmulatta } \\
\text { Mmusculus } \\
\text { Trubripes } \\
\text { Drerio } \\
\text { Dmelanogaster } \\
\text { Celegans } \\
\text { Xtropicalis }\end{array}$ & $\begin{array}{l}34 \\
20 \\
34 \\
32 \\
36 \\
33 \\
35 \\
34\end{array}$ & 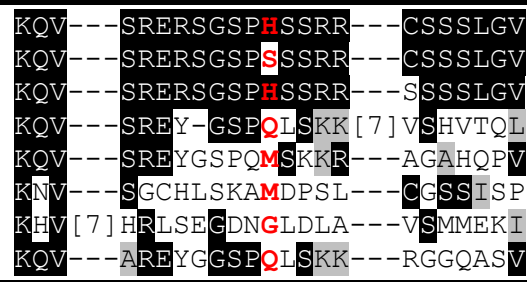 \\
\hline c. $1289 \mathrm{G}>\mathrm{A}$ & p.R430H & $\begin{array}{c}\text { possibly damaging } \\
(0.512) \\
-\mathbf{-}-\boldsymbol{-}-\boldsymbol{-}-\boldsymbol{-} \\
0.82 / 0.81\end{array}$ & $\begin{array}{c}\text { tolerated } \\
\boldsymbol{-} \mathbf{-}-\mathbf{-}-\mathbf{-}- \\
0.12 / 2.78\end{array}$ & 0.334 & 3.11 & $\begin{array}{l}\text { Human } \\
\text { Mmulatta } \\
\text { Mmusculus } \\
\text { Trubripes } \\
\text { Drerio } \\
\text { Dmelanogaster } \\
\text { Celegans } \\
\text { Xtropicalis }\end{array}$ & $\begin{array}{l}430 \\
416 \\
428 \\
435 \\
431 \\
431 \\
423 \\
431\end{array}$ & $\begin{array}{l}\text { GERRPAWT---DRRRRGPQD---RASSGD } \\
\text { GERRSAWT---DRRRRGPQ---------- } \\
\text {--RRPTWA---ERRRRGPQD---RGYSGD } \\
\text { KKGHGTWN---ERKKKG-FE---RMSIAD } \\
\text {----GTWN---ERKKKG-FE---RMSVGE } \\
\text { SLDRKSSTSS EDQLRRKAND [ 5] ------- } \\
\text { PMMMSQCT ---TASGAVLTT---AGQSQD } \\
\text {-ERKGTWN---ERKRKA-FE---RLSVGD }\end{array}$ \\
\hline c. $1358 \mathrm{C}>\mathrm{T}$ & p.T453M & $\begin{array}{c}\text { probably damaging } \\
(0.974) \\
-\mathbf{-}-\boldsymbol{-}-\boldsymbol{-}-\boldsymbol{-} \\
0.59 / 0.93\end{array}$ & $\begin{array}{c}\text { damaging } \\
\boldsymbol{-} \mathbf{-}-\boldsymbol{-}-\boldsymbol{-} \\
0.00 / 2.78\end{array}$ & 0.303 & 4.15 & $\begin{array}{l}\text { Human } \\
\text { Mmulatta } \\
\text { Mmusculus } \\
\text { Trubripes } \\
\text { Drerio } \\
\text { Dmelanogaster } \\
\text { Celegans } \\
\text { Xtropicalis }\end{array}$ & $\begin{array}{l}453 \\
439 \\
451 \\
458 \\
454 \\
482 \\
465 \\
454\end{array}$ & $\begin{array}{l}\text { DACSF-SGFRPAT----LTVTNFFKQEA } \\
\text { DACSF-SGFRPAT----LTVTNFFKQEA } \\
\text { DACSF-SSFRPAT----LTVTNFFKQEA } \\
\text { DTCNE-ATFRPAT----LTVTNFFKQEG } \\
\text { DMCNE-TNFRPAT----LTVTNFFKQEG } \\
\text { DFANVVENFRPIT----ITVPSFFKQEA } \\
\text {------GTSAAT [37] LKFSSFIRQEG } \\
\text { ETCGL-HTERPAT---LTVTNFFKQEG }\end{array}$ \\
\hline c. $1445 \mathrm{C}>\mathrm{T}$ & p.P482L & $\begin{array}{c}\text { probably damaging } \\
(0.991) \\
\mathbf{-}-\mathbf{-}-\mathbf{-}-\mathbf{-}-\mathbf{-} \\
0.50 / 0.95\end{array}$ & $\begin{array}{c}\text { damaging } \\
\boldsymbol{-}-\boldsymbol{-}-\boldsymbol{-}-\boldsymbol{-} \\
0.00 / 2.76\end{array}$ & 0.416 & 4.42 & $\begin{array}{l}\text { Human } \\
\text { Mmulatta } \\
\text { Mmusculus } \\
\text { Trubripes } \\
\text { Drerio } \\
\text { Dmelanogaster } \\
\text { Celegans } \\
\text { Xtropicalis }\end{array}$ & $\begin{array}{l}482 \\
468 \\
480 \\
487 \\
483 \\
511 \\
531 \\
482\end{array}$ & $\begin{array}{l}\text { DLFKFLADMRRPSSLLRRLRPVT } \\
\text { DLFKFLADMRRPSSLLRRLRPVT } \\
--------- \text { RPSSLLRRLRPVT } \\
-- \text { YKFLADMRRPSSVLRRLRPVT } \\
\text { DLYKFLADMRRPSSVLRRLRPVT } \\
\text { DLYKILPELKRP---------- } \\
\text { DIYRICSEMRRTNGKVHK-KMFN } \\
-------- \text { RRPSTALRRLRPVT }\end{array}$ \\
\hline
\end{tabular}


Sukalo et al. (2015), Human Mutation, Supporting Material

Supp. Table S5: Prediction of pathogenicity and conservation of DOCK6 unclassified missense variants. (continued)

\begin{tabular}{|c|c|c|c|c|c|c|c|}
\hline $\begin{array}{l}\text { Nucleotide } \\
\text { alteration }\end{array}$ & $\begin{array}{c}\text { Predicted } \\
\text { effect }\end{array}$ & $\begin{array}{c}\text { PolyPhen-2 } \\
\text { HumVar } \\
\text { [sensitivity/specificity] }\end{array}$ & $\begin{array}{c}\text { SIFT } \\
\text { [Score/Median } \\
\text { information content] }\end{array}$ & MutPred & GERP & \multicolumn{2}{|c|}{$\begin{array}{c}\text { Alignment } \\
\text { (numbers indicate position of mutated protein) }\end{array}$} \\
\hline c. $2104 \mathrm{G}>\mathrm{A}$ & p.G702S & $\begin{array}{c}\text { benign }(0.211) \\
-\mathbf{-}----- \\
0.88 / 0.74\end{array}$ & $\begin{array}{c}\text { damaging } \\
-\mathbf{-}-\mathbf{-}-\mathbf{-}- \\
0.02 / 2.74\end{array}$ & 0.389 & 3.62 & $\begin{array}{l}\text { Human } \\
\text { Mmulatta } \\
\text { Mmusculus } \\
\text { Trubripes } \\
\text { Drerio } \\
\text { Dmelanogaster } \\
\text { Celegans } \\
\text { Xtropicalis }\end{array}$ & 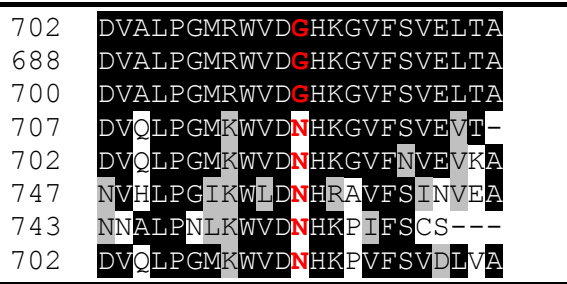 \\
\hline c. $2767 \mathrm{G}>\mathrm{A}$ & p.V923I & $\begin{array}{c}\text { benign }(0.029) \\
-\mathbf{-}-\mathbf{-}-\mathbf{-}-- \\
0.94 / 0.59\end{array}$ & $\begin{array}{c}\text { tolerated } \\
-\mathbf{-}-\mathbf{-}--- \\
0.12 / 2.71\end{array}$ & 0.327 & 3.53 & \begin{tabular}{|l} 
Human \\
Mmulatta \\
Mmusculus \\
Trubripes \\
Drerio \\
Dmelanogaster \\
Celegans \\
Xtropicalis
\end{tabular} & 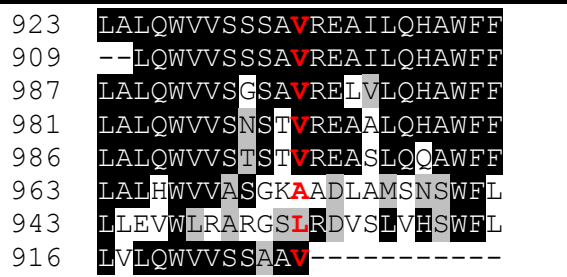 \\
\hline c. $3913 \mathrm{C}>\mathrm{T}$ & p.R1305C & $\begin{array}{c}\text { benign }(0.259) \\
-\mathbf{-}-\mathbf{-}-\mathbf{-}-- \\
0.87 / 0.75\end{array}$ & $\begin{array}{c}\text { damaging } \\
-\mathbf{-}-\mathbf{-}-\mathbf{-}-- \\
0.00 / 2.71\end{array}$ & 0.559 & 2.50 & $\begin{array}{l}\text { Human } \\
\text { Mmulatta } \\
\text { Mmusculus } \\
\text { Trubripes } \\
\text { Drerio } \\
\text { Dmelanogaster } \\
\text { Celegans } \\
\text { Xtropicalis } \\
\end{array}$ & 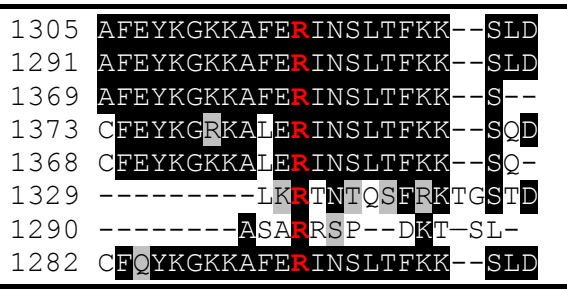 \\
\hline c. $4732 \mathrm{C}>\mathrm{T}$ & p.L1578F & $\begin{array}{c}\text { possibly damaging } \\
(0.453) \\
0 .----- \\
0.83 / 0.80\end{array}$ & $\begin{array}{c}\text { damaging } \\
-\mathbf{-}-\mathbf{-}-\mathbf{-}- \\
0.02 / 2.71\end{array}$ & 0.594 & 4.21 & $\begin{array}{l}\text { Human } \\
\text { Mmulatta } \\
\text { Mmusculus } \\
\text { Trubripes } \\
\text { Drerio } \\
\text { Dmelanogaster } \\
\text { Celegans } \\
\text { Xtropicalis }\end{array}$ & 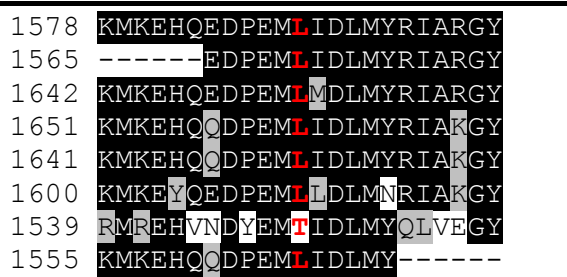 \\
\hline
\end{tabular}

Legend: see above (Supp. Table S2). 
Sukalo et al. (2015), Human Mutation, Supporting Material

\section{Supp. References}

1000 Genomes Project Consortium, Abecasis GR, Altshuler D, Auton A, Brooks LD, Durbin RM, Gibbs RA, Hurles ME, McVean GA. 2010. A map of human genome variation from population-scale sequencing. Nature 467:1061-73. Erratum in: Nature 473:544.

Adzhubei IA, Schmidt S, Peshkin L, Ramensky VE, Gerasimova A, Bork P, Kondrashov AS, Sunyaev SR. 2010. A method and server for predicting damaging missense mutations. Nat Methods 7:248-9.

Adzhubei I, Jordan DM, Sunyaev SR. 2013. Predicting Functional Effect of Human Missense Mutations Using PolyPhen-2. Curr Protoc in Hum Genet 76:7.20:7.20.1-7.20.41.

Altschul SF, Gish W, Miller W, Myers EW, Lipman DJ. 1990. Basic local alignment search tool. J Mol Biol 215:403-10.

Brunak S, Engelbrecht J, Knudsen S. 1991. Prediction of Human mRNA Donor and Acceptor Sites from the DNA Sequence. J Mol Biol 220:49-65.

Cooper GM, Stone EA, Asimenos G; NISC Comparative Sequencing Program, Green ED, Batzoglou S, Sidow A. 2005. Distribution and intensity of constraint in mammalian genomic sequence. Genome Res 15:901-13.

den Dunnen JT, Antonarakis SE. 2000. Mutation nomenclature extensions and suggestions to describe complex mutations: a discussion. Hum Mutat 15:7-12.

Exome Variant Server, NHLBI GO Exome Sequencing Project (ESP), Seattle, WA (URL: http://evs.gs.washington.edu/EVS/) [Jan, 2015].

Fokkema IF, Taschner PE, Schaafsma GC, Celli J, Laros JF, den Dunnen JT. 2011. LOVD v.2.0: the next generation in gene variant databases. Hum Mutat 32:557-63.

Lehman A, Stittrich AB, Glusman G, Zong Z, Li H, Eydoux P, Senger C, Lyons C, Roach JC, Patel M. 2014. Diffuse angiopathy in Adams-Oliver syndrome associated with truncating DOCK6 mutations. Am J Med Genet A 164A:2656-62.

Li B, Krishnan VG, Mort ME, Xin F, Kamati KK, Cooper DN, Mooney SD, Radivojac P. 2009. Automated inference of molecular mechanisms of disease from amino acid substitutions. Bioinformatics 25: 2744-50.

Ng PC, Henikoff S. 2003. SIFT: Predicting amino acid changes that affect protein function. Nucleic Acids Res 31:3812-4.

Reese MG, Eeckman FH, Kulp D, Haussler D. 1997. Improved Splice Site Detection in Genie. J Comp Biol 4:311-23.

Shaheen R, Faqeih E, Sunker A, Morsy H, Al-Sheddi T, Shamseldin HE, Adly N, Hashem M, Alkuraya FS. 2011. Recessive mutations in DOCK6, encoding the guanidine nucleotide exchange factor DOCK6, lead to abnormal actin cytoskeleton organization and Adams-Oliver syndrome. Am J Hum Genet 89:328-33.

Shaheen R, Aglan M, Keppler-Noreuil K, Faqeih E, Ansari S, Horton K, Ashour A, Zaki MS, AlZahrani F, Cueto-Gonzalez AM, Abdel-Salam G, Temtamy S, et al. 2013. Mutations in EOGT confirm the genetic heterogeneity of autosomal-recessive Adams-Oliver syndrome. Am J Hum Genet 92:598-604.

Untergrasser A, Cutcutache I, Koressaar T, Ye J, Faircloth BC, Remm M, Rozen SG. 2012. Primer3 new capabilities and interfaces. Nucleic Acids Res 40:e115.

Wildeman M, van Ophuizen E, den Dunnen JT, Taschner PE. 2008. Improving sequence variant descriptions in mutation databases and literature using the Mutalyzer sequence variation nomenclature checker. Hum Mutat 29:6-13. 